\title{
Pricing contingent convertibles: a general framework for application in practice
}

\author{
Buergi, Markus P H
}

\begin{abstract}
The first contingent convertibles (CoCo) were issued in 2009, but, to date, the academic community has not given much attention to practical issues of pricing them. Combining various aspects from existing theoretical and practical literature, this paper first presents a CoCo pricing framework that allows a flexible and comprehensible valuation of real-world equity or TIER-1 ratio-triggered CoCos. The model is based on the assumption that the issuer's total asset value follows a Brownian motion, that book values reflect fair economic values in the case of financial distress, and that there is a linear relationship between straight equity and TIER-1 ratios. The pricing methodology is then applied to the Credit Suisse Buffer Capital Note issued in February 2011
\end{abstract}

DOI: https://doi.org/10.1007/s11408-012-0203-4

Posted at the Zurich Open Repository and Archive, University of Zurich ZORA URL: https://doi.org/10.5167/uzh-155772

Journal Article

Published Version

Originally published at:

Buergi, Markus P H (2013). Pricing contingent convertibles: a general framework for application in practice. Financial Markets and Portfolio Management, 27(1):31-63.

DOI: https://doi.org/10.1007/s11408-012-0203-4 


\title{
Pricing contingent convertibles: a general framework for application in practice
}

\author{
Markus P. H. Buergi
}

Published online: 20 January 2013

(C) Swiss Society for Financial Market Research 2013

\begin{abstract}
The first contingent convertibles (CoCo) were issued in 2009, but, to date, the academic community has not given much attention to practical issues of pricing them. Combining various aspects from existing theoretical and practical literature, this paper first presents a CoCo pricing framework that allows a flexible and comprehensible valuation of real-world equity or TIER-1 ratio-triggered CoCos. The model is based on the assumption that the issuer's total asset value follows a Brownian motion, that book values reflect fair economic values in the case of financial distress, and that there is a linear relationship between straight equity and TIER-1 ratios. The pricing methodology is then applied to the Credit Suisse Buffer Capital Note issued in February 2011.
\end{abstract}

Keywords Contingent convertible $\cdot$ Pricing $\cdot$ Equity ratio trigger

JEL Classification $\mathrm{G} 12 \cdot \mathrm{G} 13 \cdot \mathrm{G} 18 \cdot \mathrm{G} 21$

\section{Introduction}

Recent turmoil in financial markets has revealed the fragility of modern financial institutions and the financial system itself. One result of the bursting of the US housing bubble, the subsequent subprime mortgage crisis, and the recent sovereign debt crisis has been a call for better capitalization of financial institutions. Furthermore, government rescue of several large banks brought the issue of so-called too big to fail banks to the attention of regulators and the public. The Basel Committee on Banking Supervision (2011) has already included related elements in Basel III, the new global

M. P. H. Buergi $(\bowtie)$

Department of Banking and Finance, University of Zurich, Pattenstrasse 14, 8032 Zurich, Switzerland

e-mail: markus.buergi@sfi.ch 
regulatory standards on bank capital adequacy and liquidity. Compared to preceding standards, the liquidity and minimum capital required by Basel III are significantly higher. Obviously, raising additional equity capital is expensive for banks. To alleviate this problem, various regulators (e.g., the Swiss FINMA) are showing an interest in so-called contingent convertibles $(\mathrm{CoCo})$ as an alternative to additional hard equity capital.

The paper is structured as follows. Section 2 presents and discusses the extant literature on CoCo pricing. In Sect. 3, the various constituent parts of a CoCo are determined and a brief overview given of the few CoCo issues offered to date. Section 4 is concerned with the actual pricing framework. The basic concept of CoCo pricing, which is actually valid for all structural valuation approaches, is illustrated by means of a simple introductory example. This allows a clear picture and understanding of the general mechanics of the pricing methodology. Subsequently, the CoCo pricing framework to be applied in practice is elaborated and the sensitivities of the CoCo's price to changes in its three main design parameters - the coupon rate, the trigger level, and the conversion ratio-are analyzed. In Sect. 5, the pricing methodology is applied to the Credit Suisse Buffer Capital Note (BCN) issued in February 2011. Because this note is one of the few existing CoCos, and not a special case, applying the methodology to this CoCo enables identification and discussion of issues of practical implementation. Finally, Sect. 6 provides a summary and the conclusion.

\section{Existing pricing approaches}

The main distinguishing feature of different contingent convertible bond forms is the choice of trigger. Usually, this is either the share price of the issuing firm, as is the case for classical convertibles, or an accounting ratio. Later in the paper, it is shown that, in practice, conversion is usually coupled to some kind of equity ratio, and this is actually the main issue when pricing CoCos. On the one hand, the question is how to model the expected path of the trigger that determines the probability of conversion. On the other hand, given a fixed conversion ratio, the payoff at conversion depends on the corresponding market stock price. However, the stock price may not be in a perfect, or any standardizable, relation with the trigger. This means that it is not possible to perfectly determine the expected payoff at conversion, ex ante.

To date, most CoCo pricing approaches, such as Flannery and Mark (2009), McDonald and Robert (2010), and Sundaresan et al. (2010), are very conceptual and primarily focus on a rather qualitative analysis. Furthermore, these approaches rely on stock price rather than on equity ratio triggers. Thus, their practicability is limited. The first practical approaches to real-world valuations of contingent convertibles were published in 2010. These approaches are of two main types: structural or derivatives.

Structural valuation models usually rely on the option pricing methodology of Black et al. (1973) and Merton and Robert (1973). Those presented by Raviv and Alon (2004), Pennacchi and George (2010), and Albul et al. (2010) assume that the bank's total asset value follows a Wiener process, while the value of the deposit, subordinated bond, and equity capital tranches are modeled on the asset value. Pennacchi and George (2010) additionally integrates jump-diffusion processes, which reflect the possibility 
of sudden large losses in asset value. In both models, triggering the CoCo depends on the asset value or some book value to asset value ratio. Such structural approaches model dependencies in the issuer's capital structure and their impact on the triggering probability and provides valuable insight into the corresponding mechanics. However, determining the corresponding factors in practice may be extremely difficult. Neither Pennacchi and George (2010) nor Albul et al. (2010) address this issue in detail. Another structural approach is presented by Garcia and Joao (2011). He relies on the CDS and equity swap valuation methodology elaborated by Brigo et al. (2005) and applies their analytically tractable first passage model to price contingent convertible bonds. The model outputs are then calibrated to the implied default probabilities from the CDS market.

De Spiegeleer et al. (2011) present two derivatives approaches. Their so-called credit derivatives approach is straightforward. Based on the distribution of stock price movements, they calculate the triggering probability and the expected loss in the case of conversion. This results in the credit spread necessary to cover the corresponding investment risks. The alternative equity derivatives approach is basically a payoff replication. The CoCo is separated into three parts: a zero-coupon corporate bond, the coupon payments, and the block of shares received if converted. Each part is valued individually. Valuation of the corporate bond part is rather simple; however, coupon payments are modeled as multiple binary-down-in options and the block of shares as a knock-in forward. Provided that triggering relies on a stock price trigger, valuation of all parts is unproblematic. In practice, however, triggering usually depends on an equity or TIER-1 ratio. The authors bypass this issue in both approaches by replacing the equity ratio trigger level with a representative stock price level. This implies a direct relationship between equity ratio and stock price. Furthermore, neither approach accounts for callability nor, even more importantly, the impact of a CoCo issue on the issuer's capital structure, profitability, and, thus, the triggering probability. This impact probably is negligible in the case of small CoCo issues but, based on the nominal amounts of existing CoCos, this effect should be taken into account.

In conclusion, CoCo valuation faces two general issues: determining the probability of triggering and determining the share price at conversion. Both issues arise from the relation between actual and disclosed asset as well as debt values. The equity ratio used as the trigger indicates the relative proportion of book equity capital to the bank's total book value of assets. These numbers are published in the firm's financial statements and follow certain accounting rules. On the contrary, the stock price or market capitalization is the economical valuation of the expected present value of the bank's future net earnings. This implies that it equals the actual asset value less the present value of all future liabilities. The equity ratio, which determines conversion, is based on book values, whereas the stock price, which determines the payoff at conversion, relies on actual asset values. Thus, the dependency between the equity ratio and the stock price is determined by deviations between the disclosed and actual values of asset and debt capital.

Obviously, the disclosed values depend in a positive way on their actual counterpart. Under current accounting standards, deviations for debt capital should be small. While the nominal amount of debt capital is perfectly reflected in the book values, future interest owed may not be. This causes a certain downside bias in book debt values that 
can be corrected if the maturities and interest rate obligations are known. However, in the case of banks, this is not always straightforward: deposits have no fixed maturity, which means that they can be withdrawn at any time. Pennacchi and George (2010) addresses this by assuming overnight maturity for deposits. However, hanging over every bank is a sword of Damocles in the form of a bank run, which, if it occurs, may have a sudden impact on the equity ratio; this situation is difficult to model. Looking at the asset value side, accounting standards usually require disclosure either at market value or at the lower of cost and market value. The latter approach is also called the minimum value or caution principle. Correspondingly, disclosed asset values are usually lower than actual ones and are more sensitive to downward turns in the actual asset value than to upward ones. Thus, the equity ratio will indeed react in the same way as the stock price to changes in the actual asset value, but given a comparably high actual asset value, the reactions of the equity ratio will be strongly dampened.

This can be illustrated by a simple example. Assuming that a firm's asset side consists of a $50 \%$ tranche disclosed by marking to market (MTM) and another $50 \%$ tranche disclosed following the minimal value principle (MVP). If the asset tranches were bought for 50 each and their market prices are always identical, then the total disclosed asset value will equal its actual counterpart only if the two parts' values are below 50. Above this threshold, only the MTM part will reflect all movements in the asset value one-to-one; the MVP part is disclosed at market price only if that is lower than its initial price. Correspondingly, the disclosed total asset value would be lower than the actual. The higher the percentage of assets disclosed by MTM, the smaller this effect and, thus, the difference between actual and disclosed asset values. Hence, when modeling the conversion probability based on actual asset values, the model will indicate conversion too late but will become more precise at lower trigger levels. Returning to our example, if we assume a trigger level represented by an asset value of 110, the disclosed asset value undercuts this threshold far earlier than the actual one. If the level is 105 , this distance is already much smaller and, given a level less than or equal to 100 , it is zero.

\section{Constituent parts of a CoCo and current issues}

Before addressing the question of how to price contingent convertible bonds, the constituent parts of a CoCo are briefly described. This is followed by an overview of recent CoCo issues by banks, which gives an idea of their use and design in practice.

\subsection{Price determinants and design parameters}

The fair price of a contingent convertible is determined by various factors, which stand in interdependent relationships. Like every convertible bond, the CoCo can be decomposed into a bond and an equity part. As long as the CoCo has not been converted, it behaves like a normal straight bond paying a periodic coupon and redemption at maturity. The risk of conversion could be compared to a default risk with no recovery at all. If the CoCo is converted, the value of this bond part becomes zero. On the other hand, in this case, the value of the equity part is no longer zero, but becomes 


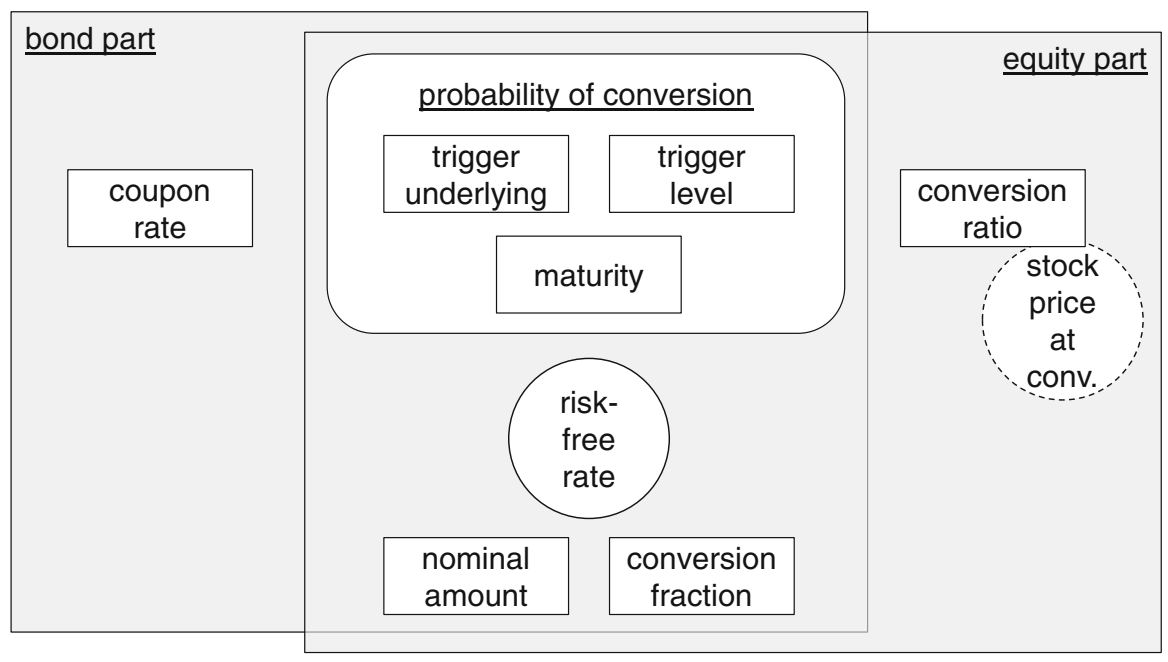

Fig. 1 Constituent parts of a contingent convertible. The constituent parts of a CoCo can be assigned to its bond part or its equity part. Besides this, they may have an impact on the probability of conversion. In this figure, the design parameters that can be set at the issuer's discretion are displayed as rectangles, whereas circles represent given determinants

positive. Finally, the expected value of both parts chiefly depends on the probability of conversion. If the probability of conversion is very low, the bond part accounts for most of the CoCo's total value, whereas the proportion of the equity part is low. With a high probability of conversion, the opposite is true. Figure 1 illustrates the CoCo pricing system.

Let us first look at the probability of conversion. A change in this probability has an ambiguous impact on the CoCo's total value because it depends on the direction of the value transfer induced by conversion. If, for example, the conversion ratio is zero and the CoCo bond writes down completely when triggered, a higher probability of conversion would be undesirable for CoCo investors and the CoCo's fair value would decrease. On the other hand, a very high conversion ratio may cause a value transfer to CoCo holders, so a higher probability of conversion would have a positive impact on the CoCo's value.

Maturity A bond's maturity is usually defined at issuance. When these predefined date are reached, the investor is repaid the nominal value of his/her investment. The longer the remaining life of the CoCo bond, ceteris paribus, the higher the probability of trigger and, therefore, the probability of conversion.

Trigger In the case of standard convertibles, conversion is usually coupled to the stock price. Correspondingly, the stock price at which conversion is possible and the value of the block of stocks the investor receives has a linear relationship. However, in the case of CoCos, triggering may not rely on only the stock price, but on various types of underlying values. Recent literature, such as Maes et al. (2010), classifies these into three groups: market triggers, accounting triggers, and regulatory triggers.

Market triggers are the simplest and most straightforward. Here, triggering relies on variables such as the stock price, credit spread, or CDS spread, which are defined by the 
markets and easily available any time. Based on the assumption of liquid and efficient markets, all the variables mentioned have forward-looking characteristics and should thus be plausible indicators of the bank's financial soundness. In practice, though, especially in critical situations, such assumptions may be inappropriate. For example, in the recent financial crisis, the liquidity of CDS contracts was very low. Correspondingly, even small trades can have a substantial impact on market prices, which may no longer reflect the actual economic situation. Moreover, market triggers are vulnerable to manipulation. As discussed by Flannery and Mark (2009) and McDonald and Robert (2010), either the issuer or the CoCo holder may have an incentive to force conversion if doing so will result in a positive value transfer to them.

Accounting triggers rely on accounting ratios, which give an indication of a bank's financial situation. All existing real-world CoCos have this type of trigger. They rely on the so-called TIER-1 ratios, which are defined by rules of the Basel Committee on Banking Supervision. In contrast to a normal equity ratio, which compares book equity capital to the book value of assets, in the case of the TIER-1 ratios, the value of assets is calculated by applying special risk weights to different asset types. For example, less risky assets such as government bonds are assigned a lower risk weight than below investment grade assets. This results in lower equity capital requirements for high compared to low quality assets to reach a certain TIER-1 ratio. At first sight, such book values do not depend on the liquidity or efficiency of the financial markets. Due to standardized and audited accounting standards, the manipulation problem also seems to be under control. Again, however, a look at the recent crisis raises some doubt. In the last decade, accounting standards have shown a certain tendency toward MTM rules (Plantin et al. 2008; Laux 2009). This means that if certain assets' liquidity becomes very low, as was the case for mortgage-backed securities, their book value will decrease massively, probably to much less than their actual economic value. Thus, book values also indirectly depend on market liquidity. Furthermore, between 2006 and 2009, even banks thought to be in a distressed state never published TIER-1 ratios lower than $7 \%$ (own analysis). This suggests that banks have a certain amount of discretionary leeway in determining their TIER-1 ratios. Another issue is that some banks have concerns about the potential behavior of large CoCo investors if conversion becomes very likely (Ryan et al. 2011). Large institutional investors may try to hedge the receipt of a large block of shares via massive short selling. This would drive the stock price down and most likely severely restrict the bank's capacity to act. Although this would have no immediate impact on book values or the TIER-1 ratio, the bank's profitability would suffer and-if the CoCos were equipped with a regulatory trigger as well-regulators could be induced to use their power to convert the CoCo.

Regulatory triggers give financial market supervisory authorities the discretionary right to force conversion of the CoCo. These triggers are designed to help solve the too big to fail problem. The mechanism provides the government with the opportunity to avoid expensive bailouts, which may be necessary even if not indicated by the stock price or an accounting ratio. However, regulators have to rely on certain indicatorssuch as stock price or accounting ratios-as well. Correspondingly, and as described above, regulators can be misled by manipulated indicators. However, the discretionary nature of this trigger class makes assessing the probability of conversion and thus the pricing of CoCos unpredictable, at least to some extent. 
As proposed by McDonald and Robert (2010), conversion of a CoCo could depend on not only a single trigger, but also multiple ones. The design possibilities are nearly endless, but combining a market or accounting trigger with a regulatory one seems promising. Principally, there are two options for designing the interaction between two or more triggers. An if-and design requires all trigger values to fall below the trigger level before the CoCo will convert (Squam Lake Working Group on Financial Regulation 2009). On the other hand, in the case of an if-or design, just one trigger value falling below the trigger level causes conversion. However, regardless of the potential combinations of multiple triggers, detailed information on the distribution of the trigger values is needed to assess the probability of conversion. Ceteris paribus, in any case, a higher volatility of the trigger has a positive impact on this probability.

Trigger level If the trigger falls below a certain barrier, which is called the trigger level, the CoCo is converted into shares or written down. The trigger level is defined at issuance and does not change during the lifetime of the bond.

In principle, the values of the bond and the equity parts of a CoCo can be considered separately as conditional values. The probability of conversion determines how much each part contributes to the CoCo's total value. However, there are three factors that have an impact on both the bond and the equity part.

Risk-free rate As is the case for every other financial product, the risk-free rate has an impact on the present value of future cash flows generated.

Nominal amount If a CoCo bond matures without having been triggered, the investor is paid a predefined redemption value. Usually, this value equals the nominal value of the bond. However, the equity part relies on the nominal value of the CoCo as well. The higher the nominal value, the more shares the CoCo investor receives in the case of conversion.

Conversion fraction The conversion fraction defines the portion of the nominal value that is converted into shares if the trigger is hit. If the conversion fraction is at its maximum, which means $100 \%$, the full nominal amount will be converted according to the corresponding conversion ratio. If the conversion fraction is lower than that, only the corresponding part of the nominal amount is converted. The residual amount is usually immediately returned to the investor.

The bond part of the CoCo is actually equal in structure to a standard straight bond. However, instead of default risk and a certain recovery rate, there is conversion risk and a specified conversion fraction. If there is no full conversion, the fraction redeemed immediately can be interpreted as some kind of recovery. Thus, the only remaining element that has an impact on the value of the bond part is the coupon rate.

Coupon rate Like any other bond, a contingent convertible can offer periodic coupon payments to the investor. The coupon rate, which applies to the nominal amount, can either be fixed at issuance or linked to some reference interest rate such as the Libor rate. In addition, the issuer can define the frequency of coupon payments. In the case of CoCos, coupon payments usually cease after conversion. 
The value of the equity part is, of course, determined by the number of shares the CoCo investor receives in exchange for the fraction of the nominal amount converted and the market value of the shares at conversion.

Conversion ratio/price The conversion ratio of a convertible bond determines how many shares the bond investor receives in exchange for a specified amount of face value in the case of conversion. This ratio also can be expressed as a conversion price, which can easily be calculated using the following formula.

$$
\text { conversion price }=\frac{\text { nominal amount }}{\text { conversion ratio }}
$$

The conversion ratio can be either variable or fixed at time of issuance for the whole lifetime of the CoCo.

When applying a variable conversion ratio, the investor receives a block of shares with an actual market value equal to a predefined fraction of the nominal amount to be converted. Usually, this fraction is $100 \%$, which means that the nominal amount to be converted would have exactly the same value as the block of shares into which it is converted. Correspondingly, the CoCo investor would neither suffer a loss nor make any profit because no value transfer would occur between him/her and the shareholders. Furthermore, this would mean that, theoretically, the share price at conversion would have no influence on the value of the CoCo.

A fixed conversion ratio implies a fixed conversion price. If the market price at conversion is lower than the conversion price, the investor will pay too much per share and thus receive a block of shares worth less than the nominal amount for which it has been swapped. The opposite is true for a market price higher than the conversion price.

A third possibility is to combine variable and fixed conversion ratios. A variable conversion ratio can be equipped with a predefined floor on the conversion price. For example, as long as the stock price at conversion is higher than the floor price, conversion occurs one-to-one and the investors receive the full nominal amount in shares. If the stock price is lower than the floor, conversion will rely on a fixed conversion price, equal to the floor, and the investors will suffer a loss. Depending on the level of the floor, such a mechanism can be seen as either an alternative form of protection against excessive stock price manipulation or as a simple marketing instrument, allowing unsophisticated investors to reduce the likely losses caused by conversion.

Share price at conversion The share price at conversion is only relevant for pricing a $\mathrm{CoCo}$ if it is equipped with a fixed conversion ratio. The value of the block of shares the investor receives is equal to the conversion ratio times the stock price at conversion. In the case of a stock price triggered CoCo bond, the price at conversion is usually equal to the trigger level, which means that the value of the block of shares received at conversion is already known at issuance. In the case of alternative triggers, however, it is much less clear what the stock price will be at conversion.

Similar to straight bonds and normal convertibles, most of the determinants of a CoCo's value are defined at issuance and do not change between then and maturity. The issuer is free to set the maturity, coupon rate, conversion fraction, and conversion ratio, as 
well as the trigger and the trigger level. Hence, compared to straight bonds, there are four additional design parameters.

\subsection{Contingent convertible issues in practice}

As of February 2012, only six CoCo issues had been made by banks worldwide, and there had been a single definitive announcement of a future issue. The five issues by Lloyds Banking Group, Rabobank, Zuercher Kantonalbank (ZKB), and UBS can be considered special cases. Lloyds Banking did not make a public issue but, instead, an exchange for existing preference shares, and the CoCos of ZKB, Rabobank, and UBS do not convert but write down only. This leaves the Credit Suisse issue as the first real and public CoCo issue. In the following, the six existing CoCos are briefly characterized. Table 1 provides an overview of their determinants, as discussed in the previous section.

Lloyds Banking Group In December 2009, the British Lloyds Banking Group issued its first CoCos. The so-called Enhanced Capital Notes (ECN) were not issued publicly but offered to the holders of certain TIER-1 and upper TIER-2 securities (generally known as preferred shares). Lloyds offered specific ECN series for 52 existing types of preferred shares. Finally, it issued 29 ECN series denominated in EUR and GBP, comprising a total nominal amount of GBP 7 billion and providing a 100-250 basis points (bps) interest rate increase compared to the preferred shares for which they were converted. Maturities ranged from 9 to 22.5 years and coupon rates from 6.385 to $15.000 \%$ for the EUR-denominated series and 7.588-16.125\% for the GBP-denominated ones. All the ECN series were set to convert at a fixed conversion price of GBP 0.59 if the bank's TIER-1 ratio should fall below $5 \%$.

This first CoCo issue was part of Lloyds' massive capital increase, the goal of which was to allow the partly state-owned bank to exit the UK asset insurance program. Not doing so would have meant that the government's stake in the bank would increase to more than $60 \%$. This may be one of the reasons why Lloyds was able to place the full GBP 7 billion it intended in the CoCos.

Rabobank In contrast to Lloyds Banking Group and Credit Suisse, the Dutch Rabobank is not a stock company but a federation of local credit unions, comparable to the Raiffeisen banks in other European countries. Due to its organizational form, the conversion of a CoCo into shares is not possible. Thus, the CoCos issued by Rabobank are of a special nature in that instead of being converted into shares, the nominal amount is simply written down to some extent. This can be viewed as a CoCo with a conversion ratio equal to zero. So far, Rabobank has issued two slightly different types of CoCos.

In March 2010, it publicly placed a so-called Senior Contingent Note (SCN) with a nominal amount of EUR 1.25 billion. This 10-year bond offers a fixed coupon rate of $6.875 \%$. Triggering occurs if Rabobank's equity capital ratio, which is defined as the ratio of equity capital to risk-weighted assets, falls below a $7 \%$ threshold. In such an event, $75 \%$ of the SCN's nominal amount is written down, and the remaining $25 \%$ immediately returned to the SCN holders. Thus, the conversion fraction is 0.75 . Note that such a redemption structure will probably result in only a partial qualification (or none at all) as TIER-1 capital under Basel III. 


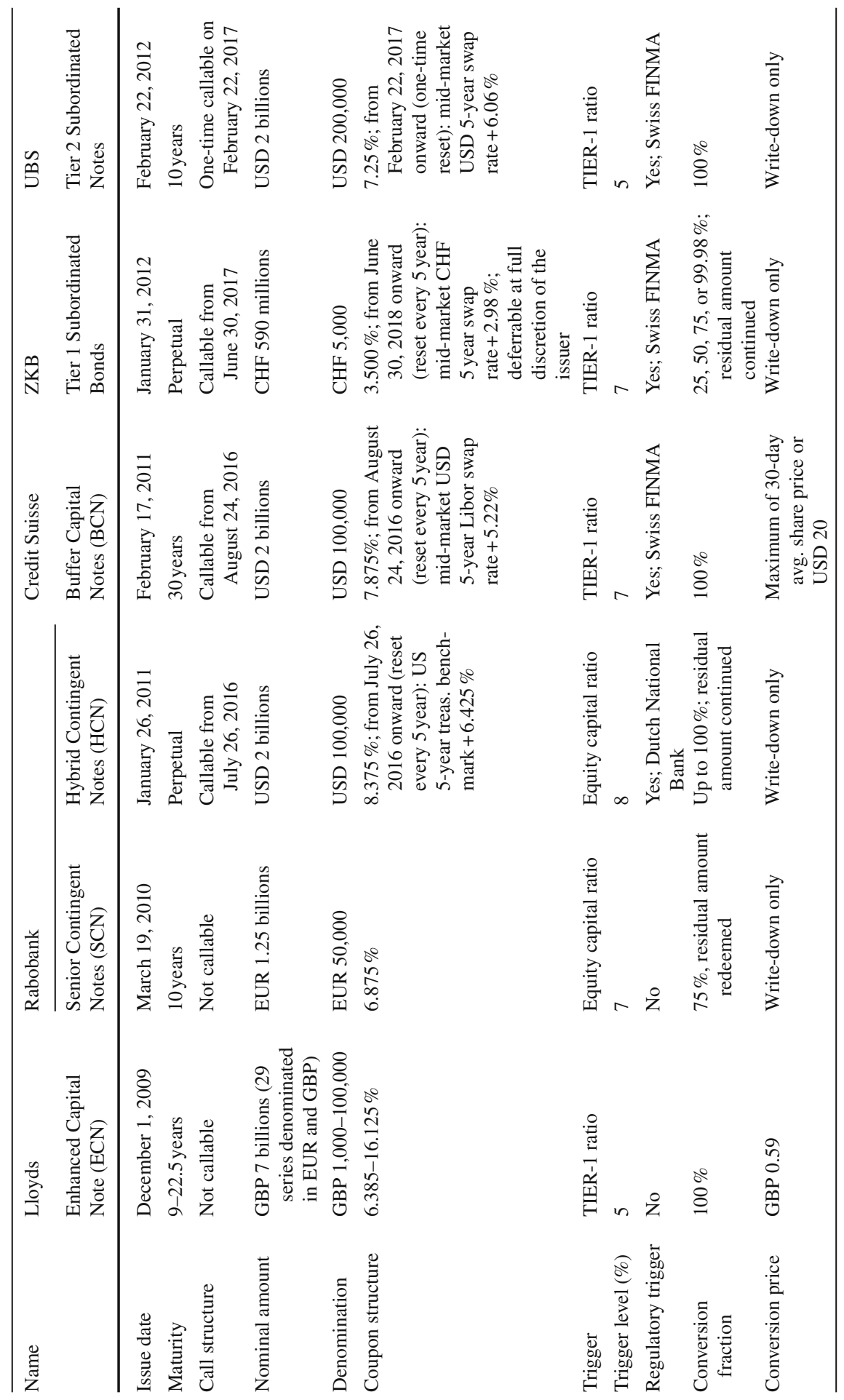


Almost a year later, in January 2011, Rabobank issued another CoCo, labeled Hybrid Capital Notes (HCN). This callable perpetual bond has a nominal amount of USD 2 billion, and the first call date is 26 July 2016. Until then, the coupon rate is fixed at $8.375 \%$, but thereafter it will be reset every 5 years to the US five-year Treasury benchmark rate plus $6.425 \%$. In addition to an accounting trigger set at an equity capital ratio of $8 \%$, the $\mathrm{HCN}$ has a regulatory trigger. If triggered, a certain fraction of the $\mathrm{HCN}$ will be written down and the residual amount will continue as a smaller HCN. The exact write-down fraction is determined by the issuer in coordination with the Dutch regulator, with the goal of restoring a sound capital basis. Such write-downs, which are also known as loss absorption events, may occur more than once. Clearly, the structure of the $\mathrm{HCN}$ is much more complex than that of the $\mathrm{SCN}$ and therefore pricing will be more demanding. However, both bonds have a conversion ratio of zero and thus show characteristics that are closer to those of preferred shares or subordinated bonds than to those of CoCos. Nevertheless, due to their write-downs relying on trigger events and not default, assessing their value requires the application of CoCo pricing approaches.

Credit Suisse In December 2010, Credit Suisse's CEO, Brady Dougan, announced that Credit Suisse planned to issue a first tranche of CoCos in 2011. Two months later, in February 2011, Credit Suisse announced a definitive agreement with Quatar Holding LLC and the Olayan Group, which would buy CHF 6 billion in CoCos to be issued no earlier than October 2013. Only a few days later, Credit Suisse publicly issued its so-called $B C N$, amounting to USD 2 billion. This 30-year security is callable by the issuer starting in August 2016. Similar to Rabobank's HCN, until that date, it pays a fixed interest rate of $7.875 \%$; afterward, the coupon rate is reset every 5 years according to the mid-market USD five-year Libor swap rate plus $5.22 \%$. Full conversion into ordinary shares in Credit Suisse will take place if the bank's TIER-1 ratio falls below $7 \%$. In addition, the Swiss regulator can trigger conversion at its own discretion. Conversion itself relies on a combination of variables and a fixed conversion ratio. The conversion price will be the higher of the floor price of USD 20 and the volumeweighted 30-day average of Credit Suisse's ordinary share price.

With the BCN, Credit Suisse was the first to actually publicly issue a real CoCo that can convert into ordinary shares. At issuance, interested investors placed orders amounting to more than USD 22 billion, a remarkable 11 times oversubscription (Whittaker and Thomas 2012).

Zuercher Kantonalbank ZKB, a Swiss universal bank wholly owned by the canton of Zurich, issued its first CoCo in January 2012. Similar to the case of Rabobank and because ZKB is a public-law institution, conversion of the CoCo into shares is not possible. Thus, triggering results in a direct write-down of the nominal amount and thus this issue also must be considered a special case of CoCo.

The so-called Tier 1 Subordinated Bonds, with a total nominal amount of CHF 590 million, are perpetual and not redeemable at any time by the investors. Only the issuer has the right to invoke early redemption, in the form of a call feature, from June 2017 onward. In addition, early redemption is possible in the event the bond will not be treated as part of the Tier-1 capital by the Swiss regulator, or if any (expected) change in the tax legislation renders ZKB exempt from national income taxes. Until this potential redemption, the bond pays a coupon rate of $3.5 \%$, which is adjusted to the mid-market 
CHF five-year swap rate plus $2.98 \%$ every 5 years from June 2018 onward. Another special feature is that the payment of interest can be (partially) suspended even before triggering. The issuer has sole discretion in this matter, whereas cancellation of interest payments will be mandatory if $\mathrm{ZKB}$ fails to maintain regulatory capital requirements. Triggering will occur if the bank's TIER-1 ratio falls below a threshold of $7 \%$ or at the discretion of the Swiss regulator. The write-down amount, which will be either 25 , 50,75 , or $99.98 \%$, will be determined by the issuer in consultation with the regulator, with the goal of restoring a TIER-1 ratio of $7 \%$. If not written down completely, the residual amount will continue as a smaller bond.

The ZKB issue combines various aspects from true CoCos, preferred shares, and hybrid TIER-1 securities (e.g., as issued by UBS between 2005 and 2008), making valuation of this security very challenging, which is probably why it is not and will not be rated.

UBS The second major Swiss bank, UBS, issued a first contingent convertible bond with a nominal amount of USD 2 billion in February 2012. In contrast to Credit Suisse's CoCos, the so-called Tier 2 Subordinated Bonds, on the one hand, feature a low-level TIER-1 trigger of $5 \%$ and, on the other hand, in the case of conversion, the nominal amount of the CoCo is not converted to shares but written down completely. Correspondingly, the UBS issue can be considered another special-case CoCo. Similar to the Credit Suisse and ZKB CoCos, it has a regulatory trigger. The 10-year security offers a $7.25 \%$ coupon rate during the first 5 years, which will then be adjusted to the mid-market USD five-year Libor swap rate plus the initial spread. At the same point in time, the issuer will have a one-time right to redeem the CoCo early. Thereafter, it will no longer be callable.

Considering the non-standardized structures of these instruments and their high denominations (mostly between USD 50,000 and USD 100,000), it is not surprising that institutionals account for the largest segment of investors (Calomiris et al. 2011). As long as the issuer's financial health does not deteriorate, investors such as insurance companies, hedge funds, and pension funds may be expected to follow a buy-and-hold strategy. This strategy is already evident in the low trading volume in the existing CoCos. However, Standard and Poor's (Brennan et al. 1977) estimate the potential market volume to be more than USD 1 trillion.

\section{A general framework for pricing equity and TIER-1 ratio-triggered CoCos}

The CoCo pricing approach presented in this paper builds on separate valuations of the CoCo's bond and equity parts and thus uses elements from Raviv and Alon (2004), De Spiegeleer et al. (2011), Garcia and Joao (2011), Pennacchi and George (2010), and Albul et al. (2010). This results in a methodology that allows both a conceptual understanding of and a practical approach to determining fair CoCo prices. The focus is on equity and TIER-1 ratio-triggered CoCos, but the basic methodology is applicable to stock price triggered bonds as well. Focusing on equity ratio triggered CoCos avoids the issue of multiple equilibria in equity and contingent capital prices, which was brought up by Sundaresan et al. (2010). 


\subsection{Assumptions}

The pricing framework is built on the following assumptions.

Assumption 1 The actual asset value follows a geometric Brownian motion.

An important assumption in much of modern finance is that equity or asset prices follow a geometric Brownian motion. In the course of their work on pricing standard convertible bonds, Brennan et al. (2010) and Ingersoll and Jonathan (1977) assume that the asset value follows a Wiener process. Following Raviv and Alon (2004), this idea is adopted for the total actual value of a company's assets $A_{a}$, as shown in Eq. 1, with $Z$ being a Wiener process.

$$
\mathrm{d} A_{a}=\mu_{A_{a}} A_{a} \mathrm{~d} t+\sigma_{A_{a}} A_{a} \mathrm{~d} Z
$$

In contrast to De Spiegeleer et al. (2011), who assume that equity prices follow a Brownian motion, this approach allows capturing the impact of default risk. Default is defined as occurring if the asset value falls below the value of liabilities or a certain fraction of it. Because a geometric Brownian motion will never fall below zero, such a default condition cannot be implemented when assuming that stock prices themselves follow a Brownian motion. For the same reason, Garcia and Joao (2011) also makes this assumption. An additional aspect is the possible payment of dividends. On the one hand, the corresponding capital outflows would reduce $\mu_{A}$, which determines the conversion probability. On the other hand, the CoCo investor would receive dividends immediately after conversion. However, it is reasonable to assume that dividends decrease with lower asset values and would probably be very low after conversion (De Spiegeleer et al. 2011). Thus, in the case of a very high dividend rate upon issuance of the CoCo, a corresponding correction factor may be added to the asset value path, whose value changes periodically depending on the actual total asset value. For the sake of clarity, the pricing framework presented here does not address this issue in any more detail.

Assumption 2 The actual asset value equals the sum of the firm's market capitalization and its actual value of liabilities.

The market capitalization, which is not necessarily equal to the book value of equity, is defined as the difference between the book value of debt capital and the actual asset value. If the asset value falls below the value of debt, default occurs and the stock price is zero. The book value of liabilities mainly consists of their redemption value, which is usually well known. It is only future interest rate payments that are not fully known. Thus, the book values should reflect the actual present value of liabilities quite well. In contrast, the book value of assets is often biased by minimum value accounting principles, hidden reserves, and the existence of intangible assets. Given efficient markets, however, these aspects should be incorporated into the market capitalization of a firm. Thus, the actual asset value should be approximated by the sum of the market value of equity and the book value of liabilities.

Assumption 3 The worse the financial condition of the firm, the more similar the actual and disclosed values of assets. 
Following the argument presented in Sect. 2, the lower a firm's actual asset value $A_{a}$, the more it will converge to the disclosed asset value $A_{d}$.

$$
\lim _{A_{a} \rightarrow 0} A_{a}=A_{d}
$$

Assuming that there is no difference between actual and disclosed values on the liability side, the equity ratio implied by the actual asset value will converge to the book equity ratio. This means that the worse a firm is doing, the better its implied equity ratio will approximate the disclosed one. However, disclosed values are usually published quarterly and exhibit a certain lag due to accounting standards. Furthermore, banks often hold assets that are very illiquid and the book values of these kinds of assets rely on banks' internal valuation models, giving banks some discretion in valuation decisions. Therefore, a bank near bankruptcy is likely to feature a higher disclosed than implied equity ratio.

A brief analysis of the price-to-book ratios of 56 US financials from the beginning of 2006 to the end of 2011 is presented in Fig. 2. During the recent financial crisis, price-to-book ratios significantly converged to one. This is confirmed by a simple linear regression of the price-to-book ratios against normalized market capitalization, which shows a degree of explanatory power $\left(R^{2}\right)$ of $44.6 \%$. In the first half of 2009 , price-to-book ratios were even significantly below $100 \%$. This is either a sign of too-high disclosed asset values or a market undervaluation of assets due to illiquid or imperfectly efficient markets. However, this supports the convergence assumption and justifies the simplification $A_{d}=A_{a}$ for CoCos with sufficiently low trigger levels since, in such cases, conversion occurs only if the issuer is in bad financial condition.

This assumption of convergence allows a hypothetical actual equity ratio to be used, which depends on the actual asset value and its well-defined return distribution. Within the range of low asset values, this actual equity ratio will converge to the disclosed equity ratio that determines conversion.

Assumption 4 The equity and the TIER-1 ratio are in a linear relationship.

As discussed above, in most of the extant CoCos triggering is not linked to the issuer's straightforward equity ratio but to the TIER-1 ratio. Calculation of this ratio is determined by the national regulators, who usually follow the guidelines set out by the Basel Committee on Banking Supervision. Aside from the value of equity capital, the TIER-1 ratio depends on the so-called risk-weighted assets. Each type of asset is assigned a specific risk weight, which should reflect the firm's exposure from holding such an asset. The risk weight for high-quality government bonds is $0 \%$, whereas that for a speculative grade corporate bond is higher than $100 \%$. Thus, there is no fixed relation between the equity ratio and the TIER-1 ratio. For example, assume that there are two banks, A and B, both with a total book asset value of USD 100 and a total equity capital equal to USD 10 . Thus, both banks have an equity ratio of $10 \%$. Now assume that bank $\mathrm{A}$ is a classic retail bank, mainly involved in savings and loans, with an average risk weight of $50 \%$. Bank B, on the other hand, is an investment bank, which is a much riskier business and thus has a higher average risk weight of $150 \%$. Thus, although they have the same equity ratio, bank A's TIER-1 ratio is $20 \%$ 


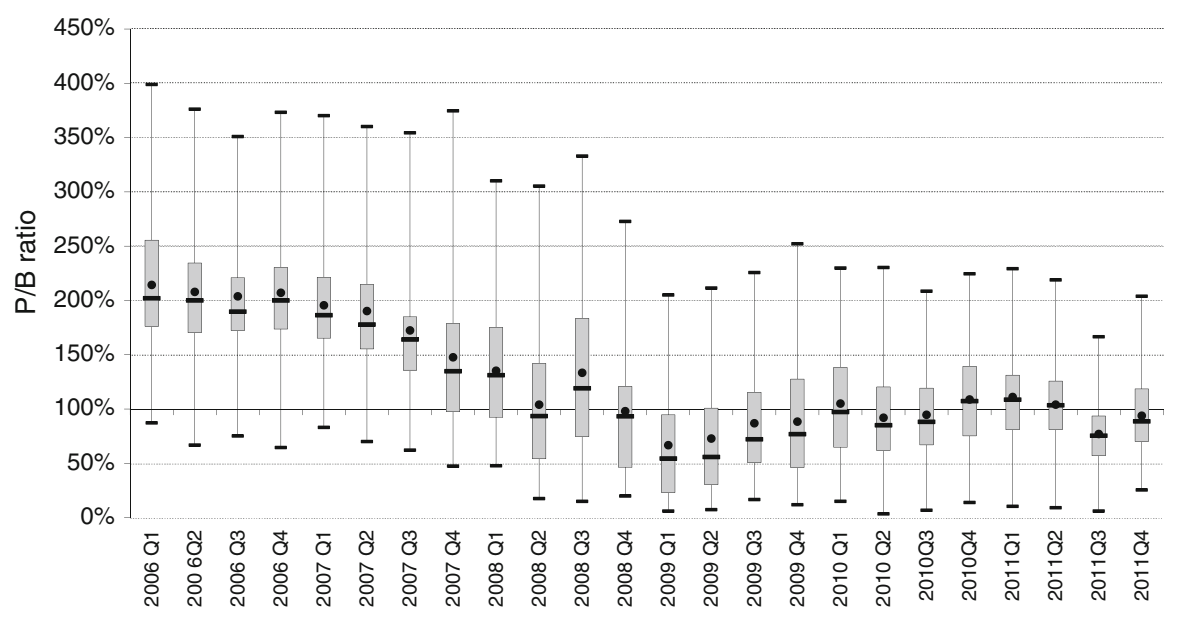

Fig. 2 Box-plot of price-to-book ratios of 56 large US financials, 2006-2011. Source: own calculations, Bloomberg

whereas bank B's is only $6.7 \%$. However, one can assume that as long as a firm does not change its business strategy and/or area completely, the asset structure will remain similar over time. Therefore, there should be a linear relationship between the equity and TIER-1 ratios (Garcia and Joao 2011).

$$
\text { TIER-1 ratio }=\alpha+\beta \text { equity ratio }+\epsilon
$$

This assumption is supported by an empirical analysis of equity ratios based on the same data set of US financials used earlier. To allow comparability between different types of banks, the equity ratios were normalized using the average of equity ratio/TIER-1 ratio. It is obvious from Fig. 3, which plots the TIER-1 ratios against the normalized equity ratios, that there actually is such a linear dependency. Furthermore, ordinary linear regression results in a highly significant dependence of the TIER-1 ratios on the normalized equity ratios and exhibits an $R^{2}$ of $63.3 \%$.

These findings suggest a simple way to transform implied equity ratios into implied TIER-1 ratios, which can be used to model the triggering probability. Of course, due to the way TIER-1 ratios are modeled and, ultimately, the fact that a firm can change its asset structure, this assumption involves a relatively high degree of uncertainty. Nevertheless, it is a valid approach for modeling this partly discretionary variable.

\subsection{Introductory example}

The conceptual foundation for pricing CoCos can be shown nicely using a binomial tree model. As mentioned above, the CoCo consists of a bond and an equity part. The expected present values of both depend on the probability of conversion. For the sake of simplicity, in this introductory example conversion does not depend on the TIER-1 ratio but on the straight equity ratio (er) as defined below. 


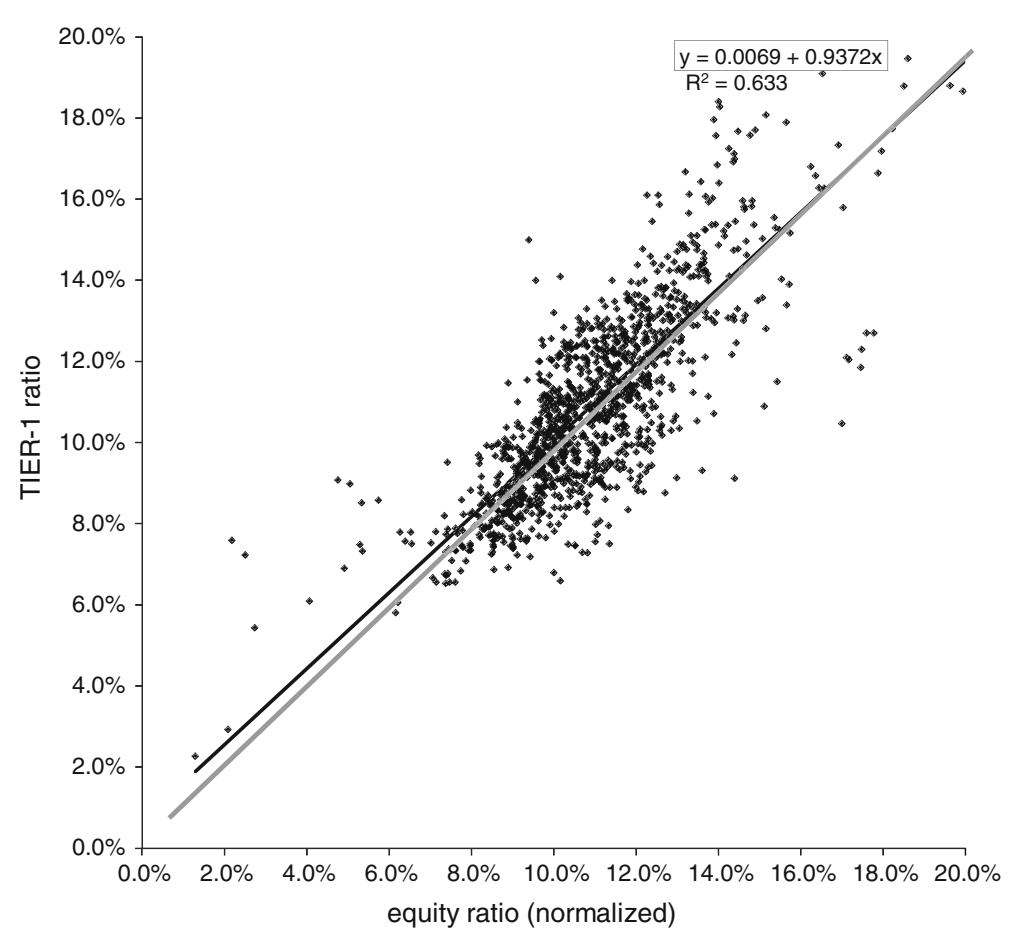

Fig. 3 Dependence between disclosed equity and TIER-1 ratios of 56 large US financials, 2006-2011. Based on disclosed data, the equity ratio is normalized using the average (equity ratio/TIER-1 ratio) across all firms, allow cross-company analysis. Source: own calculations, Bloomberg

This ratio indicates the proportion of book equity capital $E_{d}$ in the bank's disclosed total assets $A_{d}$. Book equity capital is equal to disclosed total assets less disclosed debt capital $D_{d}$. Furthermore, the disclosed asset value is assumed to equal the actual one and thus the corresponding subscripts are omitted in the explanation below.

$$
\mathrm{er}=\frac{E}{A}=\frac{A-D}{A}
$$

It is assumed that the asset yield $\mu_{A}$ is paid continuously over time and is equal to the risk-free interest rate $r_{f}$ under risk neutrality. The assets are refinanced through senior debt capital with a nominal value of $D$, a CoCo bond with face value $C$, and an equity tranche $E$. The CoCo triggers if the equity ratio falls below er* and the conversion price is $\mathrm{cp}$.

Now, the distribution of the asset value can be translated into a binomial tree following Cox et al. (1979). A simple four-period example is used to illustrate the mechanics of pricing CoCos. At the starting point of the tree, the bank has the following capital structure: a total actual asset value $A$ with a value of 100 , debt capital $D$ amounting to 80 , and a CoCo tranche of 10 . Correspondingly, the equity capital $E$, which is just one share, is worth 10 . During each period, $A$ will either increase by $5 \%$ or decrease 


$$
\begin{aligned}
& \text { Not triggered }
\end{aligned}
$$

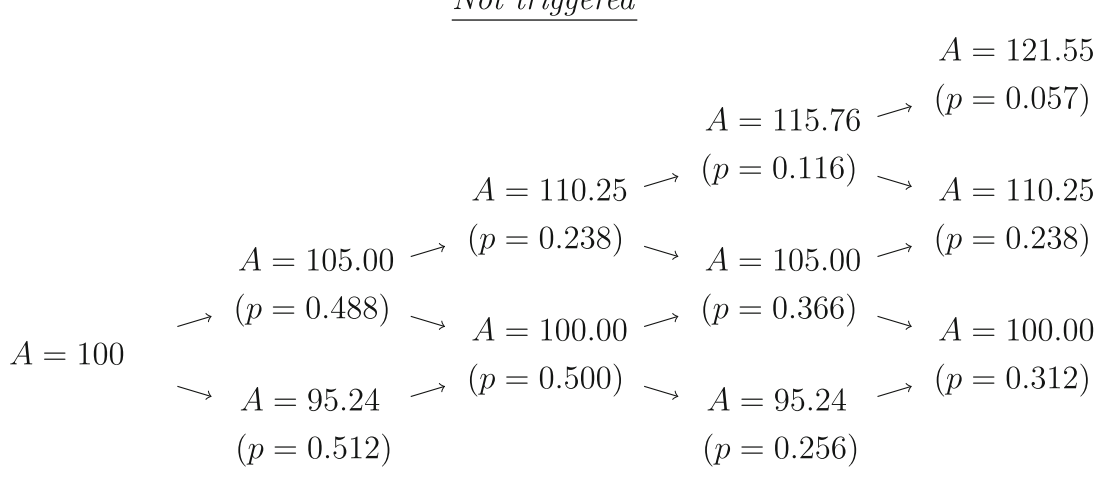

Triggered

$$
\begin{aligned}
A=95.24 \longrightarrow(p=0.062) \\
A=900.00 \\
(p=0.128) \longrightarrow A=90.70 \\
(p=0.262) \longrightarrow A=0.262) \\
(p=0.134) \longrightarrow A=82.27 \\
\\
(p=0.069)
\end{aligned}
$$

Fig. 4 Asset value distribution and state probabilities in a four-period binomial model. The binomial tree is based on the propositions of Cox et al. (1979). The initial asset value A is 100; the up and down factors are 1.05 and 1.0476, respectively. Corresponding probabilities are 48.8 and $51.2 \%$. The total amount of debt amounts to 90 . If the asset value falls below 94.7 (equals an equity ratio of $5 \%$ ) the CoCo will be triggered immediately. The lower partial tree presents the states and probabilities $p$ given prior and actual triggering

by $4.76 \%$, with probabilities 0.488 and 0.512 , respectively. For convenience, we set the risk-free interest rate to zero.

Conversion of the CoCo bond depends on the equity ratio, and the trigger level is $5 \%$. Hence, given a static total nominal amount of debt and CoCo capital of 90, a $5 \%$ equity ratio corresponds to an asset value of 94.7. Thus, the CoCo will convert if the asset value falls below this threshold. In such a case, given a conversion price (cp) of 10, the CoCo will be converted into exactly one share, which means that the former sole shareholder and the CoCo investor will have equal shares in the bank. The tree of state probabilities can now be separated into two conditional ones. The upper partial tree in Fig. 4 presents the probabilities given no conversion, and the lower tree the probabilities given present or prior conversion. We can see that, at certain nodes, such as the middle one in the last period, the CoCo can either be triggered or not.

Now we turn to valuation of the bond and equity parts of the CoCo. The value of the bond part primarily depends on the redemption value of the CoCo and its coupon payments. Similar to the equity derivative approach of De Spiegeleer et al. (2011), 


$$
\begin{aligned}
& A=121.55 \\
& A=115.76 \rightarrow V_{C}=- \\
& A=110.25 \rightarrow V_{C}=10.5 \longrightarrow A=110.25 \\
& A=105.00 \longrightarrow V_{C}=10.5 \longrightarrow A=105.00 \longrightarrow V_{C}=- \\
& A=100 \longrightarrow V_{C}=10.31 \longrightarrow A=100.00 \longrightarrow V_{C}=10.5 \longrightarrow A=100.00 \\
& V_{C}=8.85 \rightarrow A=95.24 \rightarrow V_{C}=9.15 \rightarrow A=95.24 \rightarrow V_{C}=- \\
& V_{C}=7.45 \quad V_{C}=7.86
\end{aligned}
$$

Fig. 5 Fair CoCo values. Based on the binomial tree presented in Fig. 4, a CoCo with redemption value of 10 and a coupon of 0.5 (paid every second period if not triggered) exhibits the fair values $V_{C}$ shown at the nodes that do not involve prior or actual triggering

the expected redemption and coupon payment are examined separately. If the CoCo matures in the last period, the probability of full redemption at maturity is $60.7 \%$. Thus, the expected redemption value of the CoCo is $60.7 \% \times 10=6.07$. Given a two-period coupon frequency, a first coupon will be paid at the end of the second period and a second one at the time of redemption. We assume a coupon rate of $5 \%$ or 0.5 per two periods and that coupons are paid only if the CoCo is not converted. Thus, the expected value of the first coupon payment is $73.8 \% \times 0.5=0.37$ and the value of the second is $60.7 \% \times 0.5=0.30$. This results in an expected coupon value of 0.67 and a total value of the bond part of 6.74 .

Determining the value of the equity part is done similarly. Relying on the relation between the values of assets and equity, as presented above, after conversion of the $\mathrm{CoCo}$, the equity is always worth the value of the assets minus the outstanding debt of 80 . At the end of the last period, this difference will be 20 with a $6.2 \%$ probability, 10.70 with a $26.2 \%$ probability, or 2.27 with a $6.9 \%$ probability. As explained above, in the case of conversion, the CoCo investor is assigned exactly $50 \%$ of the bank and its value. Thus, the equity part of the CoCo is worth 2.10 .

Adding up the values of all the parts, the total expected value of the CoCo is 8.85 at the first node. Hence, if the issue took place at the root of the tree and yielded the full 10, the CoCo was overpriced. However, after calculating the fair CoCo prices at all nodes, as shown in Fig. 5, it can happen that the CoCo is worth more than its nominal value.

\subsection{CoCo pricing in practice}

The pricing framework presented in this paper consists of the following three main steps:

1. determination of the issuer's actual asset value and the corresponding volatility;

2. assessment of the relationship between the actual equity ratio and the TIER-1 ratio;

3. valuation of the CoCo's redemption, coupon, and equity parts. 
Table 2 Data necessary for pricing a TIER-1 ratio triggered CoCo

\begin{tabular}{|c|c|c|}
\hline Symbol & Description & Form \\
\hline$A_{a}$ & Actual asset value of the issuer & Historical time series \\
\hline$\sigma_{A_{a}}$ & Volatility of returns on the issuer's actual asset value & Current value \\
\hline$D_{d}$ & Disclosed debt capital of the issuer & Historical time series \\
\hline$T 1$ & Issuer's TIER-1 ratio & Historical time series \\
\hline$r_{f, i}$ & Risk-free interest rate curve & Current values \\
\hline$C$ & Redemption value & Single value \\
\hline$c_{C}$ & Coupon ratio & Single value \\
\hline $\mathrm{cp}$ & Conversion price & Single value \\
\hline $\mathrm{cf}$ & Conversion fraction & Single value \\
\hline $\mathrm{er} * / T 1^{*}$ & Trigger level of equity or TIER-1 ratio & Single value \\
\hline$T$ & Remaining time to maturity & Current value \\
\hline
\end{tabular}

Additional historical time series of the market value of equity and/or credit spreads may be needed to determine $A_{a}$ and $\sigma_{A_{a}}$

In the first step, the issuer's actual asset value $A_{a}$ and its volatility $\sigma_{A_{a}}$ need to be determined. Given a sufficiently large time series of actual asset values $A_{a}$, disclosed debt capital $D_{d}$, and the TIER-1 ratio $T 1$, the second step involves analyzing the relationship between the actual equity ratio and the TIER-1 ratio. This allows the translation of the triggering criterion into a corresponding asset value threshold $A_{a}^{*}$. The third step is the actual valuation, for which the CoCo is divided into three parts: redemption, coupon, and equity. Each is valued separately and their sum represents the CoCo's fair value. Table 2 summarizes all the data and/or information necessary for pricing a TIER-1 ratio triggered CoCo.

\subsubsection{Determination of actual asset value and corresponding volatility}

When implementing a pricing approach built on the assumptions above, the question arises as to how to measure the asset value and volatility. Because such values are not directly observable, one has to rely on asset values and volatilities implied by certain indicators, such as the stock price or credit spreads. Here, we first focus on determination of implied asset values and then present various approaches for calculating implied asset volatilities.

The simplest approach for estimating the total actual value of assets is to rely on book values or, in other words, the disclosed total asset value $A_{d}$. However, following Assumption 3, these values are plausible only if the firm's financial condition is poor. In contrast, and in accordance with Assumption 2, the implied asset value can also be based on the sum of disclosed total debt capital and market capitalization $D_{d}+E_{a}=A_{a}$. Alternatively, following Black et al. (1973) and Merton and Robert (1974), the market capitalization could be seen as the actual value of a call option on the firm's equity capital. The strike price of such a call equals the company's liabilities due at a certain point in the future. Given adequate historical data on market 
capitalization and capital structure, this results in an implied asset value as well. A similar methodology, discussed in detail by Bharath et al. (2004), is chosen by Moody's KMV (Crosbie et al. 2003) in the context of assessing implied default probabilities. On the other hand, and as presented by Nikolova and Stanislava (2003), this approach can be implemented by relying on credit or CDS spreads.

There are also multiple ways of determining implied volatility. A simple method is to rely on the volatility of the market capitalization $E_{a}$. Based on the boundary condition of Merton and Robert (1974), the implied asset volatility can then be expressed as a function of $E_{a}$, its historical variance, and the total book value of liabilities $D_{d}$.

$$
\sigma_{A_{a}}=\sigma_{E_{a}} \frac{E_{a}}{A_{a}}=\sigma_{E_{a}} \frac{E_{a}}{E_{a}+D_{d}}
$$

This simple approach implies a perfect correlation between market capitalization and total asset value. Correspondingly, the triggering asset value can be translated directly into a triggering market capitalization or stock price. De Spiegeleer et al. (2011) choose this approach in their pricing methodologies. Alternatively, the credit markets can be used to determine asset volatility. The price of debt capital and/or the credit spreads directly reflect the default probability and therefore the asset volatility as well. Schonbucher and Philipp (2003) discusses CDS pricing in detail. Here, the mechanics are presented in a simplified manner. It is assumed that default is possible only at the contract's maturity. If default was possible at any point during the CDS's lifetime, one would have to rely on the work of Su et al. (2009) in a similar way to what is shown later in Eq. 12. When relying on CDS spreads, the default probability PDCDS implied by the 1 -year CDS spread in basis points, $s_{\mathrm{CDS}, 1 \text { year }}$, can be determined as shown in Eq. 6. The average recovery rate of the underlying, rr, has to be considered as well.

$$
\mathrm{PD}_{\mathrm{CDS}}=\frac{s_{\mathrm{CDS}, 1 \text { year }} / 10,000}{1-\mathrm{rr}}
$$

Given that default occurs if the asset value $A$ falls below the total amount of debt $D$ and $\Phi(x)$ being the cumulative distribution function of a normal standard distribution, the probability of default can now be derived as shown in Eq. 7. When doing so, one can rely either on the actual asset value implied by the book value $A_{d}$ or that implied by the equity markets $A_{a}$.

$$
\mathrm{PD}_{\mathrm{CDS}}=\Phi\left(\frac{\ln \left(\frac{D_{d}}{A}\right)-\left(r_{f}+0.5 \sigma_{A}^{2}\right)}{\sigma_{A}}\right)
$$

By combining Eqs. 6 and 7, the implied asset volatility can be found. However, this approach is subject to a major problem. As mentioned above, the maturity of the CDS may be chosen to be 12 months and therefore the amount of debt capital the firm must be able to repay at this point in time has to be defined. To this point, it has been 
assumed that the firm must be able to repay the total amount of debt. In practice, of course, this so-called default point will be smaller than the total amount of liabilities. The default point may lie somewhere between the short- and the long-term liabilities. In the special case of banks, studies such as Ronn et al. (1986) set the default point between 95 and $98 \%$ of total liabilities. Considering that banks' liabilities usually consist to a large extent of deposits and short-term liabilities to other banks, such values seem plausible.

In summary, it is difficult to make a clear-cut assessment of the different approaches to determining implied asset values and volatility. Output from each approach may vary substantially and the precision of the results will mainly depend on the corresponding market efficiency. However, this is an issue that affects every default and/or debt valuation model. Choosing the right methodology is probably one of the main difficulties in pricing CoCos.

\subsubsection{Assessment of relationship between the actual equity ratio and the TIER-1 ratio}

Assessing the relationship between the actual equity ratio (er) and the TIER-1 ratio $T 1$ basically relies on some type of regression analysis. The very basic approach is to model the dependency of $T 1$ on er using a linear regression model. Better results may be achieved by applying more sophisticated methods and/or adding more explanatory variables. For reasons of simplicity, in the following, it is assumed that er $=T 1$.

\subsubsection{Valuation of the three CoCo parts}

Once the necessary information about the actual asset value, its volatility, and the relationship between the equity and TIER-1 ratios has been collected, it becomes possible to value the CoCo. One of the main differences between the introductory example and the situation in practice is that, in real-life, CoCos that rely on a book value trigger can usually convert only on or just after reporting dates, which usually occur just four times per year, that is, at the end of every quarter. These points in time will be called conversion points in this paper. Correspondingly, in the period between two conversion points, the actual equity ratio could fall below the trigger level without triggering the CoCo. The same is assumed for default, which also can only occur at such conversion points. Given that the following calculations are completely based on actual values, the corresponding subscripts are omitted for ease of interpretation.

Following the first three assumptions, the trigger for the equity ratio, er*, can be translated into a trigger for the asset value, $A^{*}$, as shown below. If the CoCo relies on the bank's TIER-1 ratio for its trigger, then this equation can be combined with the corresponding formula that determines the relationship between the equity ratio and the TIER-1 ratio, as shown in Eq. 3. For the sake of clarity, we assume in what follows that the TIER-1 ratio is exactly equal to the straight equity ratio.

$$
A^{*}=\frac{L}{1-\mathrm{er}^{*}}
$$


Given the asset yield $\mu_{A}$, which is still assumed to be equal to the risk-free rate $r_{f}$, and volatility $\sigma_{A}$, we can determine the cumulative distribution function (cdf) of the corresponding Brownian motion. Equation 9 reflects the probability that the asset value is greater than $A^{*}$ at a specific point in the future, $t_{1}$. This is equal to the probability that the equity ratio lies above its trigger at $t_{1}$, causing the CoCo to trigger.

$$
P\left[A_{t_{1}} \geq A^{*}\right]=1-\Phi\left(\frac{\ln \left(\frac{A^{*}}{A_{t_{0}}}\right)-\mu_{a}\left(t_{1}-t_{0}\right)}{\sigma_{A} \sqrt{t_{1}-t_{0}}}\right) \quad \text { with } \mu_{a}=\mu_{A}-0.5 \sigma_{A}^{2}
$$

If $t_{1}$ is the remaining time to the next conversion point, Eq. 9 reflects the probability that the $\mathrm{CoCo}$ is not triggered. However, the lifetime of a CoCo usually covers more than just one conversion point and, therefore, probabilities of conversion need to be determined for all conversion points until maturity. Thus, if $t_{2}$ is the second conversion point, the probability that the CoCo has not converted at $t_{2}$ is conditional on there having been no prior conversion at $t_{1}$. Let us now assume that from $t_{1}$ on, the time between two conversion points is always identical and equal to $t_{\Delta}$.

$$
t_{\Delta}=t_{n}-t_{n-1}
$$

With $\phi(.$.$) being the probability distribution function (pdf) of a standard normal$ distribution, the probability that a CoCo has not been triggered up to and including any given conversion point $t_{n}$ is given by Eq. 11 .

$$
\begin{aligned}
P & {\left[A_{t_{n}} \geq A^{*} \mid A_{t_{n-1}}, \ldots, A_{t_{1}} \geq A^{*}\right] } \\
& =\int_{r_{A_{1}}}^{\infty} \int_{r_{A_{2}}}^{\infty} \ldots \int_{r_{A_{n}}}^{\infty} \phi\left(x_{1}\right) \phi\left(x_{2}\right) \ldots \phi\left(x_{n}\right) \mathrm{d} x_{n} \ldots \mathrm{d} x_{2} \mathrm{~d} x_{1} \\
r_{A_{1}} & =\frac{\ln \left(\frac{A^{*}}{A_{t_{0}}}\right)-\mu_{a} t_{\Delta}}{\sigma_{A} \sqrt{t_{\Delta}}} \\
r_{A_{2}} & =\frac{\ln \left(\frac{A^{*}}{A_{t_{0}} \exp \left(\mu_{a} t_{\Delta}+\sigma_{A} \sqrt{t_{\Delta}} x_{1}\right)}\right)-\mu_{a} t_{\Delta}}{\sigma_{A} \sqrt{t_{\Delta}}} \\
& \ldots \\
r_{A_{n}} & =\frac{\ln \left(\frac{A^{*}}{A_{t_{0}} \exp \left((n-1) \mu_{a} t_{\Delta}+\sigma_{A} \sqrt{t_{\Delta}}\left(x_{1}+x_{2}+\cdots+x_{n-1}\right)\right)}\right)-\mu_{a} t_{\Delta}}{\sigma_{A} \sqrt{t_{\Delta}}}
\end{aligned}
$$

This conditional cdf requires the calculation of an $n$-times integral. Solving numerically will be very time consuming and may be substituted for by a binomial or Monte Carlo approach. De Spiegeleer et al. (2011) circumvent this problem by allowing conversion at any point in time up to $t_{n}$. They rely on Su et al. (2009), who developed an 
analytical solution to determine the corresponding probabilities. If $t_{\Delta}$ is close to zero, Eq. 11 reduces to the cdf presented in Eq. 12. This greatly simplifies the calculations but is the source of a major issue as well. If conversion is possible at any time, the share price at conversion will always be identical to the trigger level. However, if conversion is possible only at the end of every quarter, the share price and/or the asset value may lie far below the trigger value. Therefore, using the simplified approach will probably bias the CoCo's value.

$$
\begin{aligned}
P & {\left[A_{t_{n}} \geq A^{*} \mid A_{t_{n-1}}, \ldots, A_{t_{1}} \geq A^{*}, t_{\Delta}=\epsilon\right] } \\
= & 1-\Phi\left(\frac{\ln \left(\frac{A^{*}}{A_{t_{0}}}\right)-\mu_{a}\left(t_{n}-t_{0}\right)}{\sigma_{A} \sqrt{t_{n}-t_{0}}}\right) \\
& -\left(\frac{A^{*}}{A_{t_{0}}}\right)^{\frac{2 \mu_{a}}{\sigma^{2}}} \Phi\left(\frac{\ln \left(\frac{A^{*}}{A_{t_{0}}}\right)+\mu_{a}\left(t_{n}-t_{0}\right)}{\sigma_{A} \sqrt{t_{n}-t_{0}}}\right)
\end{aligned}
$$

However, the subsequent analysis will rely on Eq. 11. Given the corresponding survival probabilities for every conversion point $t$, which henceforth called $p_{t}$, both the expected redemption value and the coupon value of the CoCo can easily be determined. The redemption value of the CoCo can be computed straightforwardly. If the asset value has never gone below the conversion threshold by the time maturity is reached, the CoCo will be redeemed at par. Thus, the redemption value $V_{\text {redemption }}$ is equal to the present value of the survival probability at maturity, $p_{T}$, times the redemption value $C$.

$$
V_{\text {redemption }}=p_{T} C e^{-r_{f, T}}
$$

The expected present value of the coupon payments, $V_{\text {coupon }}$, is calculated similarly. The coupon is paid to the investor only if the CoCo has not yet been converted. Therefore, the expected present value of each coupon payment depends on the survival probability at the previous conversion point $p_{t, \mathrm{pcp}}$, the percentage coupon ratio $c_{C}$, and the corresponding risk-free rate $r_{f, t}$. The sum of all such present values is equal to the coupon value of the CoCo.

$$
V_{\text {coupon }}=\sum p_{t, p c p} c_{C} C e^{-r_{f, t}}
$$

Pricing the equity part is more difficult. The actual win or loss the CoCo investor experiences in the case of conversion depends, first, on the conversion price (cp) and the conversion fraction (cf) and, second, on the number of shares outstanding before conversion $s$. The number of new shares issued due to conversion is equal to the nominal amount of the CoCo adjusted by the conversion fraction and divided by the conversion price. Omitting the conversion fraction for reasons of clarity, this means that the share price will be additionally diluted and lowered. Thus, the share price after conversion can be determined by dividing market capitalization after conversion 
$E_{t, \text { conv }}$ by the number of shares outstanding after conversion. Therefore, after conversion, the CoCo is worth the number of shares the investor receives times the stock price after conversion.

$$
C_{t, \mathrm{conv}}=\frac{E_{t, \mathrm{conv}}}{s+\frac{C}{\mathrm{cp}}} \cdot \frac{C}{\mathrm{cp}}=\frac{E_{t, \mathrm{conv}}}{s \mathrm{cp}+C} C
$$

The value of equity given conversion, $E_{t, \text { conv }}$, depends on the value of assets $A_{t}$ and debt $D$, as shown in Eq. 16. If $A_{a}$ is insufficient to cover debt capital $D$, the issuer defaults and the CoCo capital $C$ is used to cover outstanding liabilities.

$$
E_{t, \mathrm{conv}}=\max \left(0,\left(A_{t}-D\right)\right)
$$

Due to the assumption that $\mu_{A}=r_{f}$, it is not necessary to calculate the expected present value of the equity part for each conversion point, which would require calculating a $n$-times integral similar to Eq. 11 for each of them. Instead, we calculate the expected present value of the equity part at maturity $T$ only. Therefore, the pdf for the event that the CoCo is triggered at any conversion point up to and including $T$ has to be determined. This would still require the same number of $n$-times integrals to be solved but the calculations can be greatly simplified. Using Eq. 11, the probability that the CoCo has not been triggered up to and including at maturity $T$ can be calculated. Then, the second part of Eq. 17 is the theoretical expected value of $C_{T \text {,conv }}$, given that the CoCo has not been converted. The first part of Eq. 17 reflects the unconditional expected value of $C_{T \text {, conv }}$. Thus, the combination of these two parts indirectly determines the expected value of $C_{T \text {, conv }}$, which is paid only if the CoCo has been converted at some point up to and including maturity $T$.

$$
\begin{aligned}
V_{\text {equity }} & {\left[\int_{r_{A_{T}}}^{\infty} \phi\left(x_{T}\right) C_{A_{T}} \mathrm{~d} x_{T}\right.} \\
& \left.-\int_{r_{A_{1}}}^{\infty} \int_{r_{A_{2}}}^{\infty} \ldots \int_{r_{A_{n}}}^{\infty} \phi\left(x_{1}\right) \phi\left(x_{2}\right) \ldots \phi\left(x_{n}\right) C_{A_{T}, \mathrm{uc}} \mathrm{d} x_{n} \ldots \mathrm{d} x_{2} \mathrm{~d} x_{1}\right] e^{-r_{f, T}}
\end{aligned}
$$




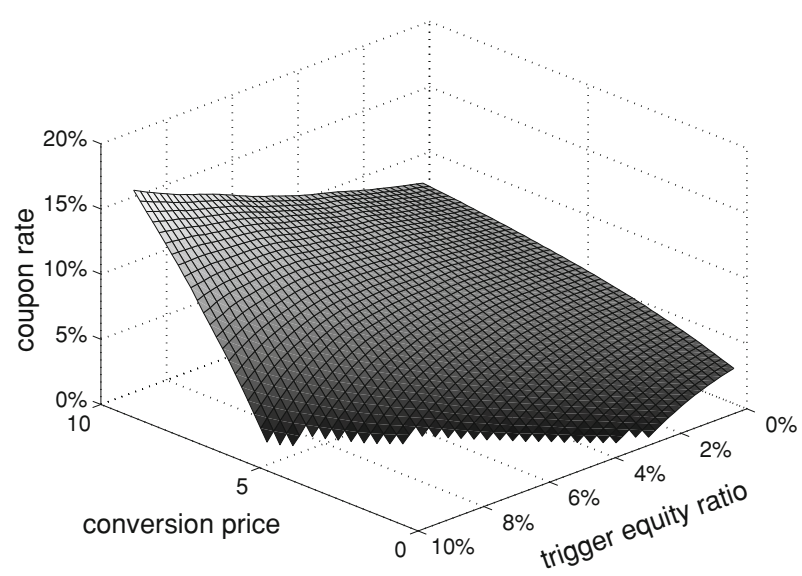

Fig. 6 Potential coupon rate/conversion price/trigger value combinations resulting in a fair price at par. $A_{t_{0}}=100, \mu_{A}=0 \%, \sigma_{A}=9.76 \%, D=80, C=10, T=2$ and the coupon frequency is 12 months. Certain combinations of conversion price and trigger equity ratio would require a negative coupon rate to result in a fair CoCo price at par and thus are not implementable

Finally, the sum of the values of all three parts is the CoCo's total value. Thus, if the probability of conversion was zero, the total value of the CoCo would be equal to the value of a risk-free government bond with identical structure and coupon rate. At the same time, $V_{\text {equity }}$ would be zero. A similar situation occurs if there is some probability of conversion and a variable conversion price that is identical to the actual share price at conversion. Then, except that the loss of future coupon payments would be higher than the risk-free rate, theoretically, the CoCo would have the same value before and after conversion. However, CoCo investors may even benefit from conversion. If the conversion price was set very low, CoCo investors would be able to take over the issuer for a price much below the market capitalization.

$$
V_{\text {CoCo }}=V_{\text {redemption }}+V_{\text {coupon }}+V_{\text {equity }}
$$

\subsection{Price sensitivities to the design parameters}

We now take a closer look at the sensitivities of $V_{\mathrm{CoCo}}$ to the three design parameters mentioned earlier: the coupon rate $c_{C}$, the trigger equity ratio er*, and the conversion price, $\mathrm{cp}$. The sensitivities and dependencies between them can be shown nicely using the example of a CoCo quoted at par. There is a large set of potential combinations $\left[c_{C}\right.$, er*, cp] resulting in a fair price equal to the nominal value. We return again to our simple example. The bank's total asset value is 100, the CoCo tranche is 10, and debt capital is 80. Again, the asset yield and the risk-free rate are assumed to be zero, while the asset volatility is $9.76 \%$. The CoCo has 2 years remaining until maturity and the coupon frequency is 12 months. Triggering is possible only every 3 months, from the date of valuation onward.

As presented in Fig. 6, if er* $=0$, both the probability of triggering and the expected present value of equity capital at conversion are minimal. Thus, the conversion price, 

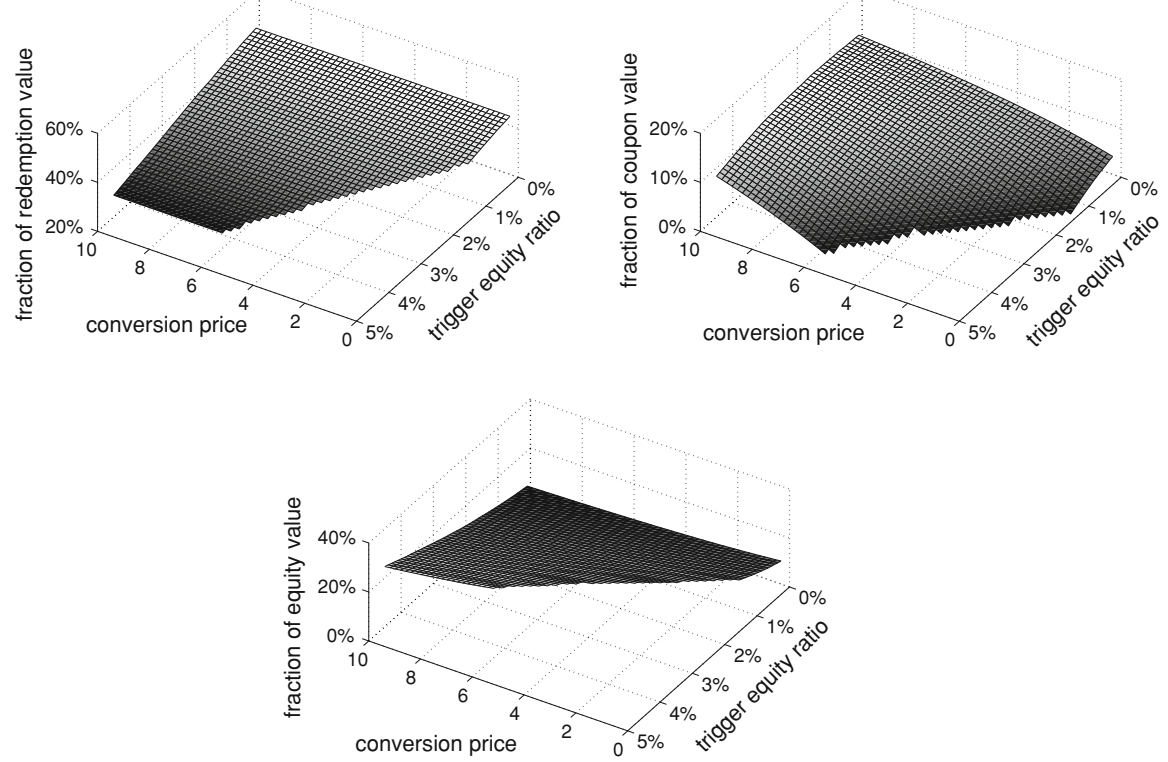

Fig. 7 Percentage shares of redemption, coupon and equity value making up the CoCo's total fair value. $A_{t_{0}}=100, \mu_{A}=0 \%, \sigma_{A}=9.76 \%, D=80, C=10, T=2$, the coupon frequency is 12 months and the CoCo value at par is fair. Certain combinations of conversion price and trigger equity ratio would require a negative coupon rate and thus are not implementable

cp, has little influence on the CoCo's price and only comparably minor adjustments have to be made to the coupon rate $c_{C}$ to maintain pricing at par. On the other hand, if er* is maximal, the probability of triggering is very high. The conversion price, $\mathrm{cp}$, now has a strong impact on the CoCo's present value. If $\mathrm{cp}$ is very high, the expected loss in the case of conversion has to be compensated for by high coupon payments. However, if cp goes to zero, the CoCo investors may take over the company for the nominal amount of the CoCo only, which may be a rather low price. This reduces the coupon rate needed to compensate for the investment risk. Due to the fact that the coupon rate cannot be negative, there are some combinations of high er* and low cp that are impossible.

Splitting up these potential $\left[c_{C}\right.$, er*, cp] CoCo structures into their three value components illustrates the mechanics discussed above. As shown in Fig. 7, the fraction the redemption value contributes to the CoCo's total value depends on the trigger level and/or the survival probability only. The fraction contributed by the equity part, on the other hand, relies in a strictly positive way on the trigger level and in a strictly negative way on the conversion price. The latter aspect is obvious; the former may not be. This positive relationship is caused by the fact that the triggering probability and thus the expected value of the equity part is increased by higher trigger levels. At the same time, the expected share price at conversion increases and, correspondingly, the value of the converted CoCo capital increases as well. Finally, the contribution from the coupon value is the residual amount, which can be seen as a compensation for expected losses in the event of conversion. 
Summing up, these results support the explanations above. Ceteris paribus, a higher coupon rate always results in a higher CoCo price, whereas a higher conversion price results in a lower CoCo price. However, the third design parameter, the trigger level, has an ambiguous impact, depending on the effective coupon rate and the conversion price. Furthermore, this simple example allows for an interesting interpretation of yield to maturity, which actually corresponds to the coupon rate if the CoCo is quoting at par. As can be seen from Fig. 6, depending on the combination $\left[c_{C}\right.$, er*, cp] yields give rise to a broad range of values. This means that comparing the cost of capital of CoCos and straight senior bonds based only on the yield to maturity is inappropriate because the securities' risk structures are completely different. Such an assessment must instead be based on the impact on the issuer's expected return on equity capital.

\subsection{Callability}

CoCos often have a call feature, meaning that after a specified date, the issuer is given the right to redeem the CoCo early, at par. This necessitates adding an analysis of optimal early redemption strategies to the pricing framework. However, in contrast to evaluation of an investor's optimal exercise strategies in the case of standard convertibles (Kind and Axel 2005; Ammann et al. 2008), evaluating early redemption by the issuer is straightforward. According to Brennan et al. (2010), the issuer's optimal call strategy for convertibles is to redeem the bond as soon as its value if called is equal to the value if not called. For example, if the bond exhibits a price above par, its coupon rate will be too high. Given no transaction cost, the issuer could lower his/her refinancing cost by calling the bond at par and then re-issuing it (at par) with a lower coupon rate. Thus, from the call date onward, the maximum price of the CoCo is limited to its redemption value, which lowers its upside potential compared to a bond without a call feature. Implementing a call feature in the pricing framework described above is possible by recursively determining and adjusting the CoCo value distribution at possible call dates. Due to space constraints, however, the mathematical formulation is not presented here.

\section{Case study: pricing the Credit Suisse BCN}

We now apply the pricing model to a real-world CoCo. As discussed above, the Credit Suisse BCN is the only CoCo issue to date that is not a special case. It was a public issue and will be converted to shares rather than simply written down if triggered. Application of the model to this CoCo will illustrate some of the practical issues involved in pricing such issues.

\subsection{Data}

For this case study, all the data needed are available from Bloomberg. The sample period spans from the issue date of the BCN, 17 February 2011, to the end of December 2011. Calculation of the equity-implied asset volatility, $\sigma_{A_{a}}$, relies on the yearly returns 
Table 3 Descriptive statistics

\begin{tabular}{|c|c|c|c|c|c|c|c|}
\hline Variable & Mean & SD & Min. & Quart. 1 & Median & Quart. 3 & Max. \\
\hline$E_{a}(\mathrm{CHF})$ & 35,625 & 9,099 & 23,639 & 26,914 & 34,354 & 44,932 & 53,366 \\
\hline$E_{d}(\mathrm{CHF})$ & 40,822 & 3,208 & 33,282 & 40,307 & 42,478 & 43,288 & 43,288 \\
\hline$D_{d}(\mathrm{CHF})$ & 978,246 & 32,086 & 936,616 & 936,616 & 973,180 & $1,019,043$ & $1,019,043$ \\
\hline$A_{a}(\mathrm{CHF})$ & $1,013,870$ & 32,522 & 960,408 & 973,691 & $1,019,649$ & $1,044,745$ & $1,051,647$ \\
\hline$\sigma_{A_{a}}(\%)$ & 5.30 & 1.30 & 3.56 & 3.85 & 5.39 & 6.63 & 6.90 \\
\hline$s_{\mathrm{CDS},} 1$ year $(\mathrm{bps})$ & 73.23 & 43.27 & 23.70 & 30.16 & 48.70 & 113.29 & 156.11 \\
\hline$\sigma_{A_{a}, \mathrm{CDS}}(\%)$ & 2.74 & 0.18 & 2.37 & 2.59 & 2.76 & 2.88 & 3.26 \\
\hline$\sigma_{A_{d}, \mathrm{CDS}}(\%)$ & 3.08 & 0.28 & 2.68 & 2.80 & 3.00 & 3.31 & 3.63 \\
\hline$r_{f, 3 \text { months }}(\%)$ & 0.11 & 0.07 & 0.00 & 0.04 & 0.17 & 0.18 & 0.19 \\
\hline$r_{f, 6 \text { months }}(\%)$ & 0.17 & 0.09 & 0.04 & 0.09 & 0.24 & 0.25 & 0.27 \\
\hline$r_{f, 9 \text { months }}(\%)$ & 0.30 & 0.11 & 0.15 & 0.18 & 0.38 & 0.39 & 0.41 \\
\hline$r_{f, 1 \text { year }}(\%)$ & 0.44 & 0.12 & 0.28 & 0.31 & 0.53 & 0.54 & 0.57 \\
\hline$r_{f, 2 \text { year }}(\%)$ & 0.28 & 0.28 & 0.00 & 0.03 & 0.20 & 0.57 & 0.84 \\
\hline$r_{f, 3 \text { year }}(\%)$ & 0.40 & 0.39 & 0.00 & 0.03 & 0.29 & 0.80 & 1.13 \\
\hline$r_{f, 4 \text { year }}(\%)$ & 0.51 & 0.37 & 0.01 & 0.18 & 0.36 & 0.89 & 1.22 \\
\hline$r_{f, 5 \text { year }}(\%)$ & 0.80 & 0.42 & 0.24 & 0.41 & 0.79 & 1.23 & 1.54 \\
\hline$V_{\mathrm{BCN}}$ & 98.59 & 5.44 & 86.76 & 93.66 & 101.79 & 103.37 & 104.44 \\
\hline
\end{tabular}

Source: own calculations, Bloomberg

during the previous 252 business days and the sample period is extended accordingly. This period occurred during a global economic downswing, which is clearly reflected in the numbers presented in Table 3.

Looking at the market capitalization and the book value of equity, the numbers already indicate a convergence, in line with Assumption 3. The first quartiles and medians of the two quantities lie at similar levels, but both the third quartile and the maximum are significantly higher for $E_{a}$. On the other hand, the minimum value is significantly higher for $E_{d}$, which is consistent with the theoretical explanations above.

Interestingly, the implied asset volatility $\sigma_{A_{a}}$, which is derived directly from the equity volatility, differs significantly from its CDS-based counterparts, $\sigma_{A_{a}}$, CDS and $\sigma_{A_{d}}$, CDS . This difference may be due to the fact that $\sigma_{A_{a}}$ relies on historical data only, whereas the CDS spreads have a forward-looking character. Another reason may have to do with the efficiency of the different markets. In the course of her much broader analysis, Nikolova and Stanislava (2003) comes to a similar finding regarding the difference in equity- and credit spread-implied asset volatilities. However, default models do not usually rely directly on implied asset volatilities but adjust them using historical default data. Summing up, determining the correct asset volatility is the first major hurdle when pricing contingent convertibles.

Interest rates during the sample period are extremely low but fairly constant. Up to a maturity of 2 years, rates lie below $1 \%$ for the whole period, and even higher maturities never have rates higher than $1.6 \%$. In addition, the volatilities of the lower 
Table 4 Descriptive statistics capital ratios

\begin{tabular}{lrllcccr}
\hline Variable & Mean & SD & Min. & Quart. 1 & Median & Quart. 3 & Max. \\
\hline er (\%) & 3.59 & 0.65 & 2.80 & 3.13 & 3.34 & 4.14 & 5.13 \\
$T 1(\%)$ & 12.37 & 2.61 & 9.00 & 10.60 & 11.60 & 13.90 & 18.20 \\
\hline
\end{tabular}

Source: Bloomberg

maturity rates are only five to six basis points, which is very low. Finally, compared to the development of market capitalization, the price of the Credit Suisse BCN is quite stable. However, the large distance between the minimum and the first quartile implies that the issue appears to have suffered a substantial drop in price during the sample period.

Information on the relationship between the equity ratio and the TIER-1 ratio is needed. Because these ratios are published only quarterly, a corresponding sample period, spanning from Q1 2002 to Q4 2011 is chosen.

According to the data presented in Table 4, the TIER-1 ratio of Credit Suisse is substantially higher than its straight equity ratio. This implies that the average risk weight of assets is very low, possibly significantly below one. This is probably the result of a rather conservative investment of assets and may be due to the bank's strong engagement in the Swiss residential mortgage and corporate loan market.

\subsection{Methodology and results}

The analysis relies on the three-step pricing framework presented above. However, several additional assumptions are made to simplify the calculations. First, and similarly to De Spiegeleer et al. (2011), the Credit Suisse BCN is assumed to feature a 5 -year maturity only. This span is equal to the call protection period of the CoCo. This assumption removes some of the CoCo's downside potential because the BCN would not be repaid after 5 years if the actual market price was below the redemption value. As a result, the outcome will be slightly too high. Second, conversion of the $\mathrm{BCN}$ is assumed to occur at reporting dates only. Because financial reports usually are not published exactly at a quarter's end but with a certain lag, the conversion points are assumed to fall exactly 1 month after each quarter's end. Third, the regulatory trigger is omitted. Determination of the CDS-implied asset volatility involves choosing a recovery rate. Following the long-term empirical studies of Altman and Edward (2003) and Moody's (2009), an expected recovery rate of approximately $55 \%$ seems plausible for secured bonds issued by financials. Fifth, the default point is defined at $98 \%$ of total liabilities.

Given these assumptions, three series of fair prices are calculated based on a binomial approach with 100,000 steps. The first series relies on the asset volatilities implied by the equity market only; the second and third calculate asset volatility using CDS spreads. For all series, the dependence of the TIER-1 ratio on the book equity ratio is assumed to stay the same. Figure 8 presents this dependency graphically. 


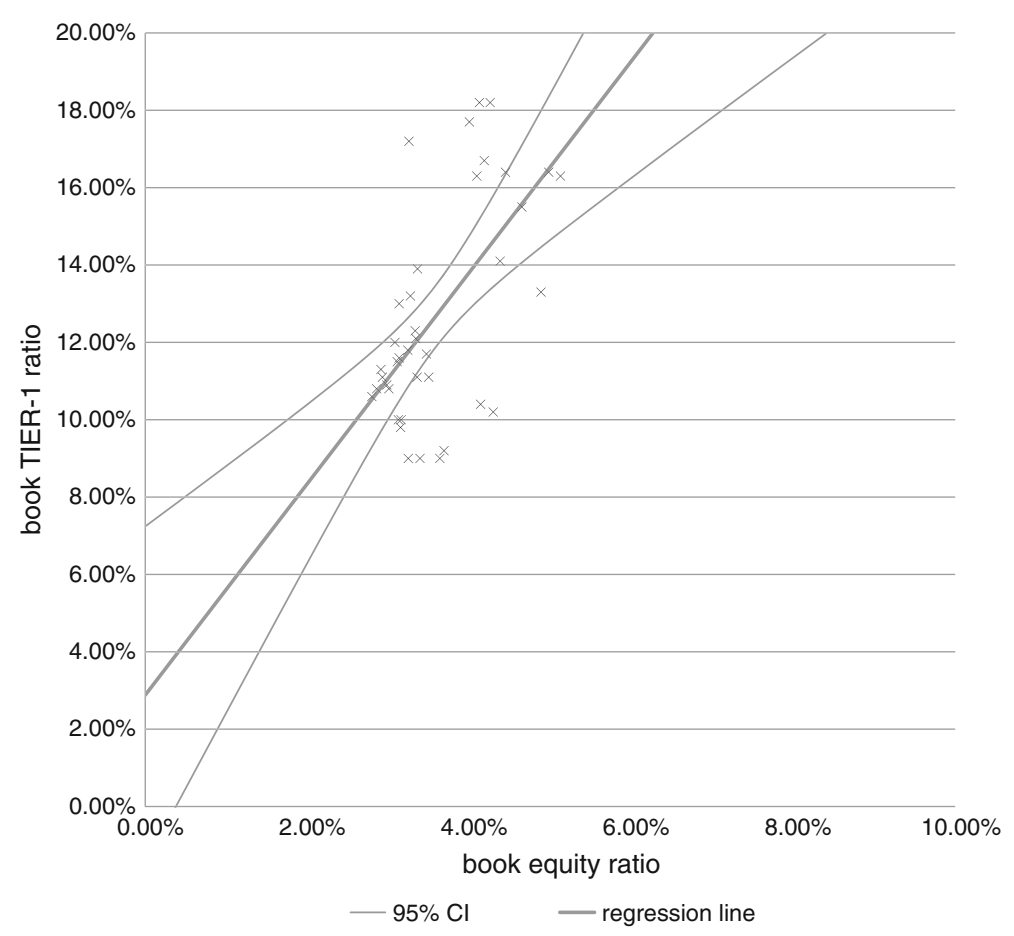

Fig. 8 Dependence between Credit Suisse's equity and TIER-1 ratios 2002-2011. Source: own calculations, Bloomberg

The intercept of the linear regression is $2.88 \%$, but the lower border of the corresponding $95 \%$ confidence interval is slightly below $0 \%$. Nevertheless, this suggests that if the bank is in financial distress, its TIER-1 ratio will be too high in an economic sense. The slope of the regression line is 2.73 , which reflects the comparably low average risk weight of Credit Suisse's assets. The $R^{2}$ of the regression is a rather low $36.03 \%$. A further uncertainty is reflected in the huge confidence interval at equity ratio ranges not represented in the historical sample. At the BCN's trigger, a TIER-1 ratio of $7 \%$, this interval varies from a corresponding straight equity ratio of $0 \%$ to approximately $2 \%$. This creates a great deal of volatility in the final price estimations and is one of the major problems when trying to price CoCos in practice.

Looking at Credit Suisse's book and implied equity ratios reveals a significant convergence during the recent crisis. After falling below the straight equity ratio during Q3 2008 and Q4 2009, the implied equity ratio often converged perfectly at the reporting dates until the end of 2011. This supports Assumptions 2 and 3, at least so far. However, in the third quarter of 2011, the implied equity ratio fell again—dramatically so.

Finally, Fig. 9 presents the model outputs for the asset volatility implied directly by the stock price volatility and those implied by the CDS spreads. The price paths modeled are approximately parallel and show a significant downturn from May 2011 onward. These downturns are primarily caused by the nearly $50 \%$ drop in the Credit Suisse stock price between May and August 2011. In the case of Models 1 and 2, this 


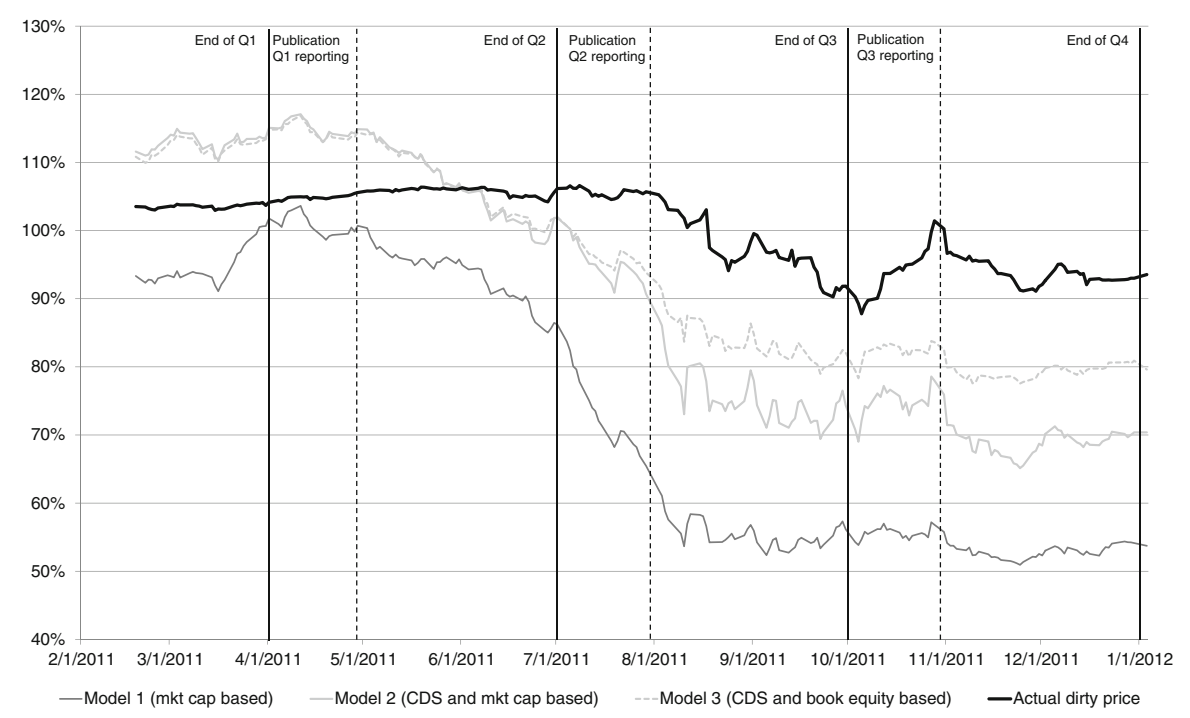

Fig. 9 Results for the Credit Suisse BCN. Model 1 relies on asset values and the corresponding volatility implied by the market value of equity and disclosed debt capital. Model 2 relies on values implied by 1-year CDS spreads, the market value of equity and disclosed debt capital. Model 3 relies on values implied by the 1-year CDS spreads, disclosed equity capital and disclosed debt capital

decreased the implied equity ratios and at the same time increased the asset volatility. Even the prices resulting from Model 3, which relies not on stock price development but on the credit spreads and the book values only, fell massively during that period. However, the actual prices of the BCN stayed relatively stable until the end of July 2011 before falling (much less steeply) as well.

The span between the prices resulting from the three models is very large, yet another indication of how difficult it is to price CoCos. In the case under consideration, credit markets seem to assume much lower asset volatility than equity markets. To this point, the CoCo market follows the credit market's assessment rather than the equity market's. However, this interpretation is based on the TIER-1 ratio being linearly dependent on the straight equity ratio presented above. If the market believed that the actual trigger asset value was lower or-in the most extreme case- that the BCN would be triggered only at default, this would actually increase the value of the CoCo. However, in the case of the Credit Suisse BCN, the regulatory trigger may avoid this extreme case, which would require a severe manipulation of the TIER-1 ratio. Nevertheless, this could be why the BCN's market price did not drop in the same way as do the modeled prices. Another explanation for the dampened reaction may lie in the expectation that, for reputation reasons, Credit Suisse would rather recapitalize in traditional ways than allow conversion occur.

\section{Conclusion}

This paper discusses the fundamentals of CoCo pricing and presents a general framework for doing so in practice. Similar to existing literature, it is assumed that the 
issuer's total asset value follows a geometric Brownian motion and that there is a certain relationship between the actual value of assets and their disclosed value. This pricing model clearly illustrates the basic mechanics of CoCo pricing and reveals three major problems that arise when attempting to price TIER-1 ratio triggered CoCos. First, determination of the TIER-1 ratio is based certain guidelines issued by national regulators but there is usually some room for discretion. As a result, modeling TIER-1 ratio's relationship on straightforward book ratios such as the equity ratio may be very difficult and require detailed information about the issuer's asset structure. Second, defining the risk of conversion or, in other words, the probability that the TIER-1 ratio will fall below the trigger value, is difficult — even if there is a well-defined dependence of the TIER-1 ratio on the straight equity ratio. It seems feasible to assume that - at least in the case of financial distress-book values reflect economically fair valuations. However, actual asset values cannot be observed directly, and thus it is necessary to rely on values implied by either equity or credit markets. Finally, the stock price at conversion, which determines the value of the block of shares received, plays an important role. Although the equity or TIER-1 ratio should be reflected in the market's valuation of the issuer, this may be only partially the case in practice, either as a result of market inefficiencies or due to the arguments mentioned above. These issues are demonstrated in the case study on pricing the Credit Suisse BCN.

In conclusion, every pricing methodology will be afflicted with these problems, thus making all results subject to a certain degree of uncertainty. What impact this will have on the development of the CoCo markets remains unknown and strongly depends on whether future banking regulations require the use of CoCo capital. However, banks may prefer the more transparent $100 \%$ write-down structures to the classical CoCo form, which allows conversion of the nominal. This is supported by the structures of the most recent CoCo issues.

Acknowledgments I thank Urs Birchler and an anonymous referee for their very helpful comments and suggestions, which made this a much sharper and improved article.

\section{References}

Albul, B., Jaffee, D., Tchistyi, A.: Contingent Convertible Bonds and Capital Structure Decisions. University of California at Berkeley, Haas School of Business (2010). (Working Paper)

Altman, E.: Default Recovery Rates in Credit Risk Modeling: A Review of the Literature and Empirical Evidence. New York University (2003) (Working Paper)

Ammann, M., Kind, A., Wilde, C.: Simulation-based pricing of convertible bonds. J. Empir. Financ. 15(2), 310-331 (2008)

Basel Committee on Banking Supervision: Basel III: A global regulatory framework for more resilient banks and banking systems. Bank for International Settlements (2011) (Technical report)

Bharath, S., Shumway, T.: Forecasting Default with the KMV-Merton Model. Department of Finance, University of Michigan Business School (2004) (Working Paper)

Black, F., Scholes, M.: The pricing of options and corporate liabilities. J. Polit. Econ. 81(3), 637-654 (1973)

Brennan, M., Schwartz, E.: Convertible bonds: valuation and optimal strategies for call and conversion. J. Finance 32(5), 1699-1715 (1977)

Brennan, M., de Longevialle, B.: Potential \$ 1 trillion bank contingent capital-style issuance faces uncertain investor interest. Standard \& Poor's (2010) (Technical Report Rating Direct)

Brigo, D., Tarenghi, M.: Credit Default Swap Calibration and Equity Swap Valuation under Counterparty Risk with a Tractable Structural Model. Banca IMI, March 8 (2005) (Working Paper) 
Calomiris, C., Herring, R.: Why and How to Design a Contingent Convertible Debt Requirement. University of Pennsylvania, Columbia Business School and Wharton School (2011). (Working Paper)

Cox, J., Ross, S., Rubinstein, M.: Option pricing: a simplified approach. J. Financ. Econ. 7, 229-263 (1979)

Crosbie, P., Bohn, J.: Modeling Default Risk: Modeling Methodology. Moody's KMV, San Francisco (2003)

De Spiegeleer, J., Schoutens, W.: Pricing Contingent Convertibles: A Derivatives Approach. Jabre Capital Partners and Katholieke Universiteit Leuven, March 18 (2011) (Working Paper)

Flannery, M.: Stabilizing Large Financial Institutions with Contingent Capital Certificates. University of Florida (2009) (Working Paper)

Garcia, J.: Pricing and Calibration of Contingent Capital with a Structural Approach. FitchSolutions (2011) (Report)

Ingersoll, J.: A contingent claim valuation of convertible securities. J. Financ. Econ. 4, 289-322 (1977)

Kind, A.: Pricing American-Style Options By Simulation. Financ. Markets Portfolio Manage. 19(1), 109_ 116 (2005)

Laux, C., Leuz, C.: The crisis of fair-value accounting: making sense of the recent debate. Account. Organ. Soc. 34, 826-834 (2009)

Maes, K., Schoutens, W.: Contingent Capital: An In-Depth Discussion. Katholieke Universiteit Leuven, August 2 (2010) (Working Paper)

McDonald, R.: Contingent Capital with Dual Price Trigger. Northwestern University, Kellogg School of Management (2010). (Working Paper)

Merton, R.: Theory of rational option pricing. Bell J. Econ. Manage. Sci. 4, 141-183 (1973)

Merton, R.: On the pricing of corporate debt: the risk structure of interest rate. J. Financ. 29, 449-470 (1974)

Moody's: Corporate Default and Recovery Rates, 1920-2008. New York University (2009) (Special Comment)

Nikolova, S.: The Informational Content and Accuracy of Implied Asset Volatility as a Measure of Total Firm Risk. University of Florida, May 15 (2003) (Working Paper)

Pennacchi, G.: A Structural Model of Contingent Bank Capital. College of Business, University of Illinois, April 15 (2010) (Working Paper)

Plantin, G., Sapra, H., Shin, H.S.: Marking-to-Market: Panacea or Pandora's Box? J. Account. Res. 46, 435-460 (2008)

Raviv, A.: Bank Stability and Market Discipline: Debt-for-Equity Swap versus Subordinated Notes. The Hebrew University Business School (2004) (Working Paper)

Ronn, E., Verma, A.: Pricing risk-adjusted deposit insurance: an option-based model. J. Financ. 41, 871-895 (1986)

Ryan, A., Crutchley, J.-P.: Schroedinger's cat. UBS Investment Research (2011) (Report)

Schonbucher, P.: Credit Derivatives Pricing Models: Models, Pricing and Implementation, 1st edn. Wiley, New York (2003)

Squam Lake Working Group on Financial Regulation: An Expedited Resolution Mechanism for Distressed Financial Firms: Regulatory Hybrid Securities. Council on Foreign Relations, Center for Geoeconomic Studies (2009) (Working Paper)

Su, L., Rieger, M.O.: How Likely is it to Hit a Barrier? Theoretical and Empirical Estimates. University of Zurich, October 24 (2009) (Working Paper)

Sundaresan, S., Wang, Z.: Design of Contingent Capital with a Stock Price Trigger for Mandatory Conversion. FRB of New York Staff, Report No. 448 (2010)

Whittaker, T.: http://www.risk.net/credit/review/2031872/credit-suisse-coco-oversubscription-dispelsconcerns-structure. Accessed on 15.02.2012

\section{Author Biography}

Markus P. H. Buergi is Program Director at Swiss Finance Institute and is responsible for several executive education programs in bank management. Previously, he worked for UBS Wealth Management Research in the field of fixed income analysis. His principal academic interests include banking regulation, capital structure management, asset pricing, and financial education. He holds an MA degree in Banking and Finance from the University of Zurich and is currently finishing his PhD in Finance at the same university. 